\title{
Article \\ Angelman Syndrome and Angelman-like Syndromes Share the Same Calcium-Related Gene Signatures
}

\author{
Julia Panov (D) and Hanoch Kaphzan *(D) \\ Laboratory for Neurobiology of Psychiatric Disorders, Sagol Department of Neurobiology, University of Haifa, \\ Haifa 3498838, Israel; juliapanov.uni@gmail.com \\ * Correspondence: hkaphzan@univ.haifa.ac.il
}

Citation: Panov, J.; Kaphzan, H. Angelman Syndrome and

Angelman-like Syndromes Share the Same Calcium-Related Gene Signatures. Int. J. Mol. Sci. 2021, 22, 9870. https://doi.org/10.3390/ ijms22189870

Academic Editors: Giuseppe Zanotti and Tito Calì

Received: 1 August 2021

Accepted: 9 September 2021

Published: 13 September 2021

Publisher's Note: MDPI stays neutral with regard to jurisdictional claims in published maps and institutional affiliations.

Copyright: (c) 2021 by the authors. Licensee MDPI, Basel, Switzerland. This article is an open access article distributed under the terms and conditions of the Creative Commons Attribution (CC BY) license (https:// creativecommons.org/licenses/by/ $4.0 /)$.

\begin{abstract}
Angelman-like syndromes are a group of neurodevelopmental disorders that entail clinical presentation similar to Angelman Syndrome (AS). In our previous study, we showed that calcium signaling is disrupted in AS, and we identified calcium-target and calcium-regulating gene signatures that are able to differentiate between AS and their controls in different models. In the herein study, we evaluated these sets of calcium-target and calcium-regulating genes as signatures of AS-like and non-AS-like syndromes. We collected a number of RNA-seq datasets of various AS-like and non-AS-like syndromes and performed Principle Component Analysis (PCA) separately on the two sets of signature genes to visualize the distribution of samples on the PC1-PC2 plane. In addition to the evaluation of calcium signature genes, we performed differential gene expression analyses to identify calcium-related genes dysregulated in each of the studied syndromes. These analyses showed that the calcium-target and calcium-regulating signatures differentiate well between AS-like syndromes and their controls. However, in spite of the fact that many of the non-AS-like syndromes have multiple differentially expressed calcium-related genes, the calcium signatures were not efficient classifiers for non-AS-like neurodevelopmental disorders. These results show that features based on clinical presentation are reflected in signatures derived from bioinformatics analyses and suggest the use of bioinformatics as a tool for classification.
\end{abstract}

Keywords: Angelman syndrome; Angelman-like syndromes; calcium signaling; RNA sequencing; transcriptome; calcium-target genes; calcium-regulating genes

\section{Introduction}

Angelman syndrome (AS) is a rare genetic neurodevelopmental disorder, manifested by a happy demeanor, severe cognitive deficits, absence of speech, susceptibility for epilepsy, and motor impairments [1-5]. Its prevalence is between 1:10,000-1:20,000 [2,6]. The cause for AS is the loss of function of the $U B E 3 A$ protein in the brain. In neurons, $U B E 3 A$ is an imprinted gene, and only the maternal gene is expressed, while the paternal gene is silenced. In $\sim 70 \%$ of AS cases, the loss of $U B E 3 A$ is due to the deletion of small portions of the maternal chromosome 15(q11-13), which contains the UBE3A gene [7-10]. Other causes of AS include unipaternal disomy, imprinting defects, and UBE3A point mutations in the maternal gene [6,11,12]. Interestingly, in about $10 \%$ of the cases, the clinical phenotype is very similar to AS; however, none of the genetic screening tests point to the above-mentioned issues, and no other genetic neurodevelopmental disorder with similar clinical manifestation is diagnosed.

In previous studies, we observed that activity-dependent calcium signaling is impaired in AS hippocampal pyramidal neurons [13]. This finding led us to investigate the expression profiles of calcium-related genes in AS [14]. We used the calcium genes database (CaDeGB) [15] to identify the calcium-related genes. These genes were divided into two categories according to their role in calcium signaling, calcium-target genes that are downstream genes affected by calcium signaling, and calcium-regulating genes that are upstream 
and modify calcium signaling. In our previous study [14], we found a list of calcium-target genes and a list of calcium-regulating genes that can serve as transcriptomic signatures for AS, distinguishing between AS mice and their healthy control littermates. Following this finding, we further demonstrated that these calcium-target and calcium-regulating genes can also serve as signatures for AS in two independent RNA sequencing datasets generated from two completely different human cellular models of AS [14]. Furthermore, we showed that other lists of randomly picked calcium-related genes were not able to serve as signatures for AS, making these found gene signatures distinctive. These results propelled us to examine these calcium-target and calcium-regulating gene signatures in a wide array of neurodevelopmental disorders, using publicly available transcriptome datasets extracted from various AS-like and non-AS-like disease models.

For the first time, we show here that the calcium-related gene signatures for AS work also as signatures for additional syndromes that are clinically termed as AS-like syndromes or that have sufficient overlap of clinical symptoms with AS. However, they do not work as signatures for syndromes that are clinically different from AS. Based on the calcium-target and calcium-regulating signature gene lists, we presented each dataset of a distinct neurodevelopmental disorder utilizing a dimensionality-reduction approach, thus demonstrating the separation of each AS-like syndrome from its healthy controls.

The significance of the herein reported results is two-fold. One, these results that are based on a bioinformatics analyses might serve as a basis for understanding the molecular pathophysiological differences between distinct neurodevelopmental disorders. Two, the herein findings suggest a novel method of developing a deeper diagnostic approach, which might alter classification methods of neurodevelopmental disorders.

\section{Results}

Our aim was to determine whether the distinct signatures of calcium-target and calcium-regulating genes that we have previously found for Angelman Syndrome (AS) [14] are shared by other neurodevelopmental syndromes and whether there is a difference between AS-like and non-AS-like syndromes. In order to examine that, we re-analyzed publicly available transcriptome datasets of neurodevelopmental disorders in light of calcium-associated genes. The evaluated syndromes were divided into two groups-ASlike and non-AS-like-based on their clinical appearance [16].

The schematic representation of the analysis steps for each dataset is presented in Figure 1.

For each studied syndrome, we obtained the raw expression matrix from the NCBI database (for full list of all datasets used in the study please refer to Table 1).

Table 1. Data sets downloaded from NCBI for analyses.

\begin{tabular}{|c|c|c|c|}
\hline Disorder & Model & GEO & Number of Samples in Each Dataset \\
\hline Rett Syndrome & $\begin{array}{l}\text { RNA-seq of cerebellum of Mecp2 knockdown male } \\
\text { mice and WT controls }\end{array}$ & GSE105045 & $\begin{array}{c}\mathrm{RTT}=3 \\
\text { Control = } 3\end{array}$ \\
\hline Rett Syndrome & $\begin{array}{l}\text { RNA-seq of postmortem brain tissue samples of } \\
\text { female patients clinically diagnosed with Rett } \\
\text { syndrome and age-matched female donors }\end{array}$ & GSE128380 & $\begin{array}{l}\text { Cingulate cortex: } \\
\text { RTT }=2 \text { and control }=2 \\
\text { Temporal cortex: } \\
\text { RTT }=3 \text { and control }=3\end{array}$ \\
\hline Pitt-Hopkins & $\begin{array}{l}\text { RNA sequencing dataset of dorsal telencephalons } \\
\text { of Tcf4-knockout, Tcf4-heterozygous, and WT mice } \\
\text { at P0 (immediately after birth) }\end{array}$ & GSE79663 & $\begin{array}{c}\text { Tcf } 4-\mathrm{KO}=3 \\
\text { Tcf } 4-\mathrm{Het}=3 \\
\text { control }=3\end{array}$ \\
\hline $\begin{array}{l}\text { Phelan-McDermid } \\
\text { Syndrome }\end{array}$ & $\begin{array}{l}\text { RNA-seq data generated from human-induced } \\
\text { pluripotent stem cell-based model (hiPSC-neurons) } \\
\text { of PMS by reprogramming peripheral blood } \\
\text { samples from individuals with PMS }(n=7) \text { and } \\
\text { their unaffected siblings }(n=6)\end{array}$ & GSE150429 & $\begin{array}{c}\text { Female } 4 \mathrm{w}: \\
\text { PMS = } 3 \text { and control }=4 . \\
\text { Female } 6 \mathrm{w}: \\
\text { PMS }=3 \text { and control }=3 . \\
\text { Female } 8 \mathrm{w}: \\
\text { PMS = } 2 \text { and control }=4 . \\
\text { Male } 6 \mathrm{w}: \\
\text { PMS }=2 \text { and control }=5 . \\
\text { Male } 8 \mathrm{w}: \\
\text { PMS }=2 \text { and control }=2 .\end{array}$ \\
\hline
\end{tabular}


Table 1. Cont.

\begin{tabular}{|c|c|c|c|}
\hline Disorder & Model & GEO & Number of Samples in Each Dataset \\
\hline Smith-Magenis Syndrome & $\begin{array}{l}\text { RNA-seq of Rai1 conditional knockouts and } \\
\text { wild-type mice }\end{array}$ & GSE81206 & $\begin{array}{c}\text { Cortex: } \\
\text { SMS }=2 \text { and control }=2 \\
\text { Hypothalamus: } \\
\text { SMS = } 2 \text { and control }=2 \\
\quad \text { Striatum: } \\
\text { SMS }=2 \text { and control }=2\end{array}$ \\
\hline Mowat-Wilson Syndrome & $\begin{array}{l}\text { RNA-seq data generated from P0 cerebellum of } \\
\text { Zeb2-cKO mice and of their WT controls }\end{array}$ & GSE84098 & $\begin{array}{l}\text { Zeb-cKO = } 3 \\
\text { Control }=3\end{array}$ \\
\hline Fragile X Syndrome & $\begin{array}{l}\text { RNA-seq dataset generated from human neural } \\
\text { progenitor cells-derived hiPSCs with a } \\
\text { midbrain-patterning differentiation protocol using } \\
\text { CRISPR/Cas9 to introduce indels in exon } 3 \text { of } \\
\text { FMR1 }\end{array}$ & GSE117248 & $\begin{array}{c}\text { FXS }=6 \\
\text { Control }=6\end{array}$ \\
\hline Kabuki Syndrome & $\begin{array}{l}\text { RNA-seq data from brains of a neuron-specific } \\
\text { Kdm6a-deficient mouse model }\end{array}$ & GSE81251 & $\begin{array}{l}\text { Kdma6a-KO = } 6 \\
\quad \text { Control }=6\end{array}$ \\
\hline Tuberous Sclerosis & $\begin{array}{l}\text { RNA-seq generated from human neural stem cells } \\
\text { derived from embryonic stem cells that have a } \\
\text { deletion (either TSC2 } \\
\text { (TSC2-KO) of the TSC2 gene }\end{array}$ & GSE78959 & $\begin{array}{c}\text { TSC2-KO }=4 \\
\text { TSC2-Het }=4 \\
\text { Control }=4\end{array}$ \\
\hline
\end{tabular}

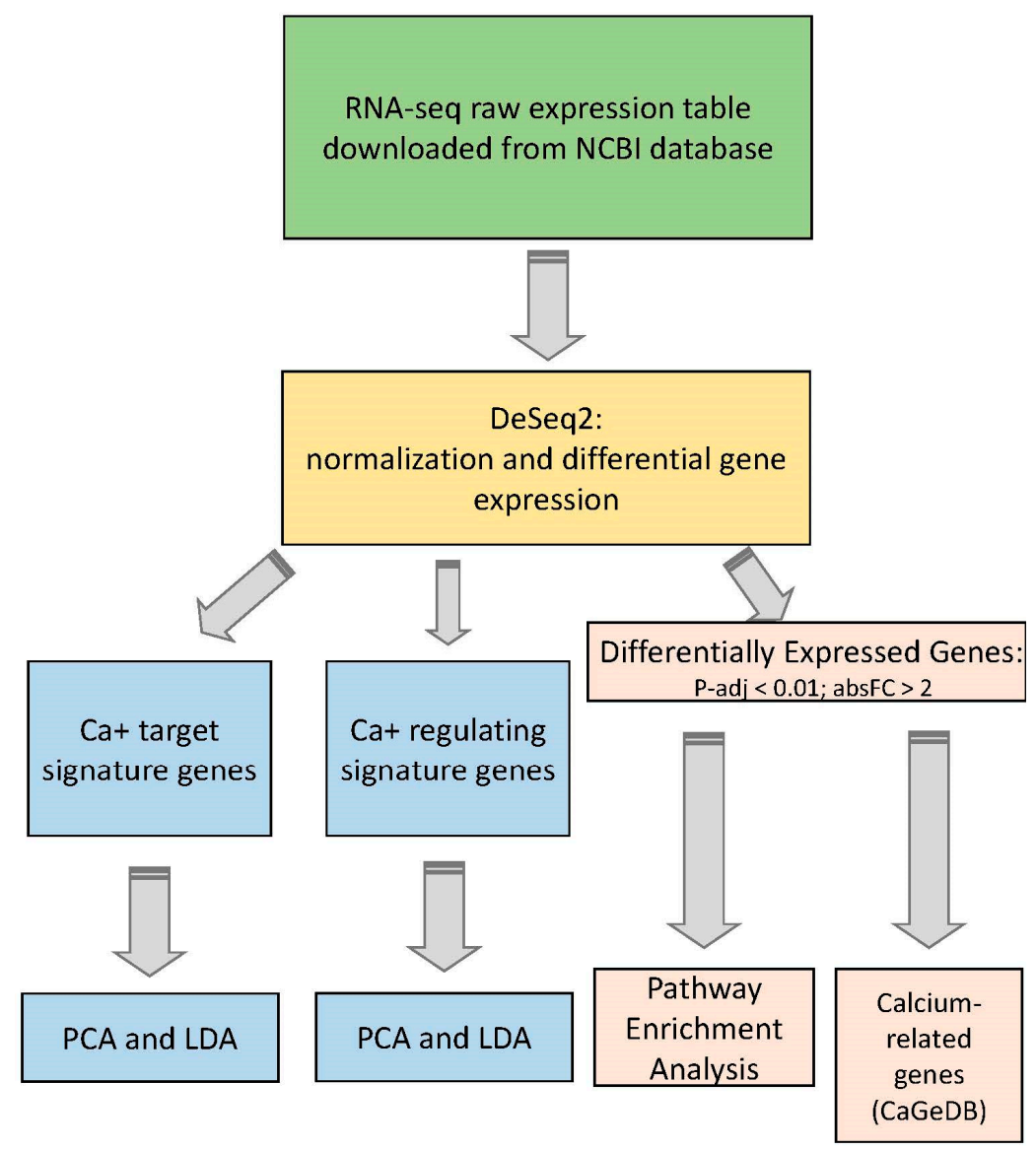

Figure 1. A schematic presentation of analysis steps for each dataset.

The raw expression matrix was normalized using a normalization algorithm implemented in the DESeq2 R package [17]. After normalization, calcium-target and calciumregulating gene signatures found in our study of calcium-associated genes in AS [14] were extracted, and a Principle Component Analysis (PCA) was performed using these two signatures separately. The PCA method $[18,19]$ compresses the multidimensional distribution of points in a space of a smaller dimension (typically two-dimensional space) with 
minimal distortion of inter-point distances. PCA analysis gave the position of samples from each dataset on the two-dimensional plane keeping the distance between samples similar to the distance based on all original dimensions, i.e., the expression of calcium-target or calcium-regulating genes. The distribution of samples on the PC1-PC2 planes was used to visualize the difference between control and disease samples and to identify whether calcium-target and calcium-regulating signatures can be used to correctly classify the studied disorder. In addition, for each disorder, we identified differentially expressed genes using the DeSeq2 algorithm [17]. Enrichment analysis of Gene Ontology (GO) terms and biological pathways was performed using the DAVID Bioinformatics Recourses tool [20,21]. Utilizing the $\mathrm{CaGeDB}$ database [15] of calcium-associated genes, we extracted differentially expressed genes that are known to be either calcium-target or calcium-regulating.

\subsection{AS like Syndromes}

\subsubsection{Rett Syndrome (GSE105045, GSE128380)}

Rett syndrome (RTT) is considered an AS-like syndrome and shares many clinical features with AS [16]. Approximately $95 \%$ of RTT cases are due to mutations in the MECP2 gene, which is located on the $\mathrm{X}$ chromosome [22]. Females partially compensate for the loss of $M E C P 2$ function with an extra intact copy on the homologous $\mathrm{X}$ chromosome, but this is not the case for males. Consequently, males have a severe phenotype and represent less than $1 \%$ of RTT patients. RTT occurs in 1 in 10-15,000 live female births, which makes it one of the most common causes of monogenic intellectual disability in females [23]. MECP2 is an X-linked gene that recognizes DNA, and histone methylation marks and modifies the transcription [23]. MECP2 is expressed in all tissues in the body with major expression in the central nervous system (CNS).

We utilized two different RNA sequencing datasets for our study with a focus on the calcium-target and calcium-regulating gene expressions. One dataset is an mRNA sequencing of cerebellum of Mecp2 knockdown mice and their wild-type littermates [24]. Another dataset is a total RNA sequencing data generated from postmortem cingulate and temporal cortices of RTT patients and healthy controls [25].

To determine whether our previously identified calcium-target and calcium-regulating signatures of AS can also discriminate Rett syndrome patients, we first studied the dataset generated from cerebellum of Mecp2 knockdown male mice (Mecp2-KO) and their wild-type (WT) controls available in the NCBI database under the accession number GSE105045 [24]. We found that in the mouse Rett model (Mecp2-KO mice), the calciumtarget and the calcium-regulating signatures found in AS were good classifiers of Rett syndrome. The calcium-target and calcium-regulating signature genes separated the Rett syndrome samples from the healthy control samples in the PC1-PC2 space well (Figure 2A,B). Unsupervised analysis of differentially expressed genes in the mouse model of Rett syndrome did not reveal significantly enriched calcium-related pathways (Supplementary Figure S1A,B); however, it has been previously shown that calcium signaling is implicated in RTT pathology $[26,27]$. Focusing on the calcium-related differentially expressed genes utilizing the $\mathrm{CaDeGB}$ database, we found that in Mecp2-KO mice, $12.5 \%$ (four genes) of all differentially expressed genes were calcium-related (Table 2, Supplementary Table S1). Interestingly, all of the calcium-related genes were downregulated in cerebellum of Mecp2-KO compared to WT control mice. 
A.

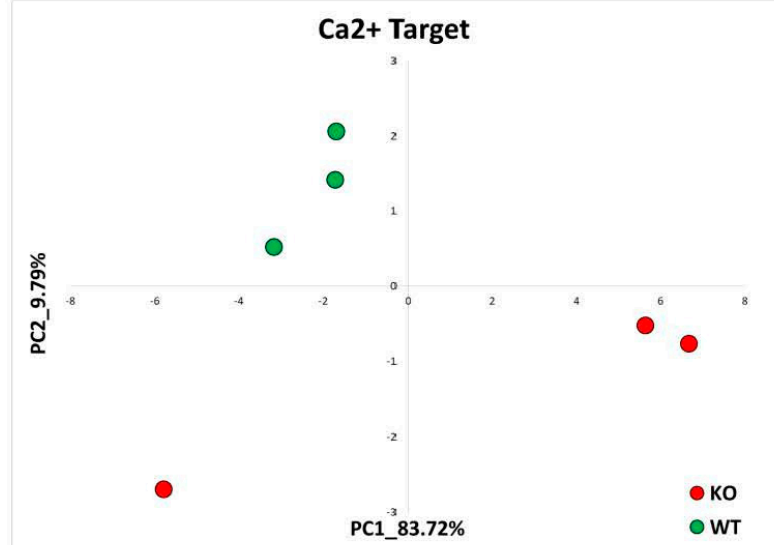

B.

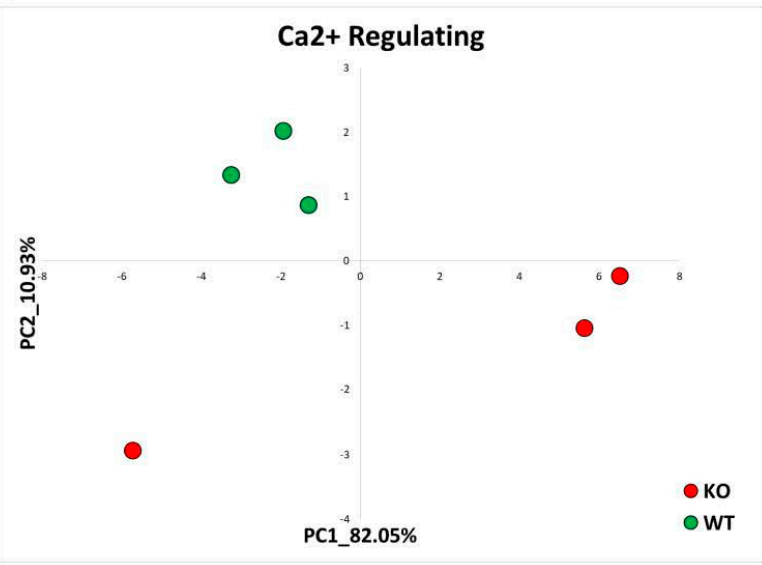

C.

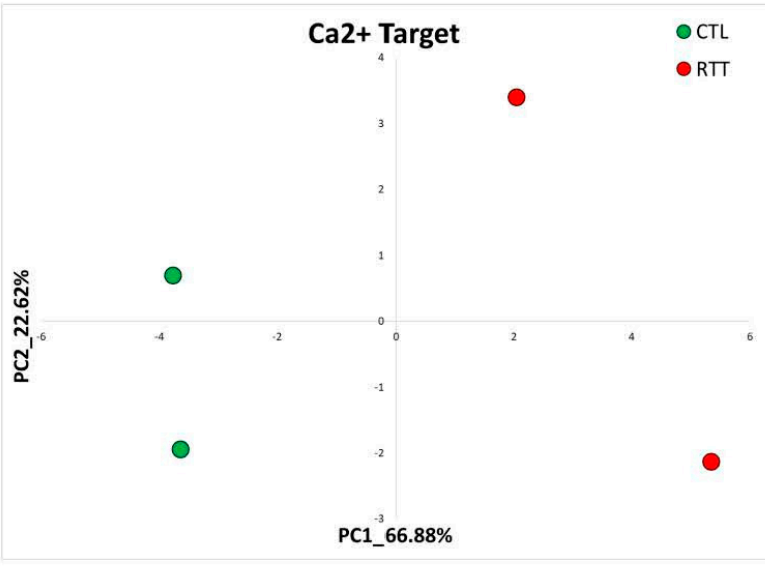

D.

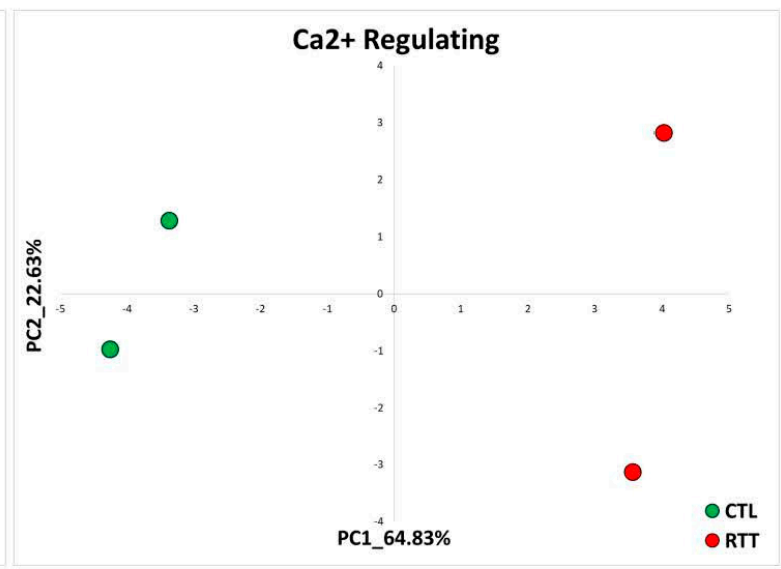

E.

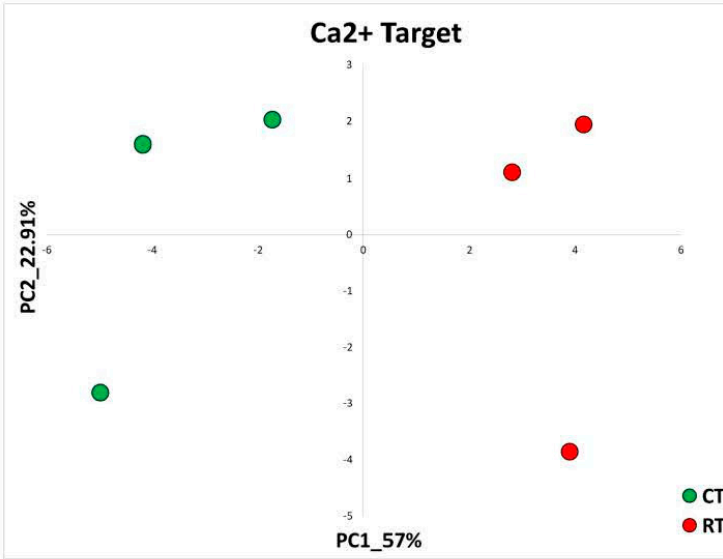

F.

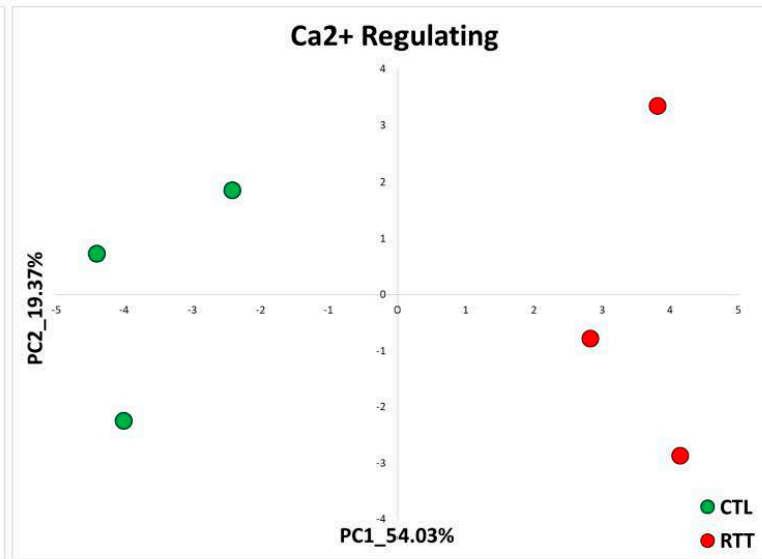

Figure 2. Rett Syndrome: ca-target and ca-regulating signatures. (A) PCA based on the expression of calcium-target signature genes in cerebellum of Mecp2-KO and WT mice. The WT samples are denoted in green, while the Mecp2-KO samples are in red. (B) PCA based on the expression of calcium-regulating signature genes in cerebellum of Mecp2-KO and WT mice. The WT samples are denoted in green, while the Mecp2-KO samples are in red. (C) PCA based on the expression of calcium-target signature genes in postmortem cingulate cortex of Rett patients and healthy controls. The control samples are denoted in green, while the Rett samples are in red. (D) PCA based on the expression of calcium-regulating signature genes in the postmortem cingulate cortex of Rett patients and healthy controls. The control samples are denoted in green, 
while the Rett samples are in red. (E) PCA based on the expression of calcium-target signature genes in the postmortem temporal cortex of Rett patients and healthy controls. The control samples are denoted in green, while the Rett samples are in red. (F) PCA based on the expression of calcium-regulating signature genes in the postmortem temporal cortex of Rett patients and healthy controls. The control samples are denoted in green, while the Rett samples are in red.

Table 2. Differentially expressed calcium-target and calcium-regulating genes.

\begin{tabular}{|c|c|c|c|c|c|c|c|}
\hline & \multirow[b]{2}{*}{ Disorder } & \multirow[b]{2}{*}{ Model } & \multicolumn{2}{|c|}{ Calcium Target } & \multicolumn{2}{|c|}{ Calcium Regulating } & \multirow[b]{2}{*}{$\begin{array}{l}\text { All Calcium } \\
\text { Related } \\
\text { DEG }\end{array}$} \\
\hline & & & $\begin{array}{c}\text { Down } \\
\text { Regulated } \\
(\% \text { from } \\
\text { Downregulated) }\end{array}$ & $\begin{array}{l}\text { Up } \\
\text { Regulated } \\
\text { (\% from Up- } \\
\text { regulated) }\end{array}$ & $\begin{array}{c}\text { Down } \\
\text { Regulated } \\
\text { (\% from } \\
\text { Downregulated) }\end{array}$ & $\begin{array}{l}\mathrm{Up} \\
\text { Regulated } \\
\text { (\% from Up- } \\
\text { regulated) }\end{array}$ & \\
\hline 1 & \multirow{3}{*}{$\begin{array}{l}1.1 \text { Rett } \\
\text { Syndrome }\end{array}$} & $\begin{array}{c}\text { Mecp2-KO } \\
\text { model } \\
(\mathrm{GSE} 105045)\end{array}$ & $3(9.37 \%)$ & $0(0 \%)$ & $1(3.18 \%)$ & $0(0 \%)$ & $12.5 \%$ \\
\hline 2 & & $\begin{array}{l}\text { Postmortem } \\
\text { brain } \\
\text { cingulate } \\
\text { cortex } \\
\text { (GSE128380) }\end{array}$ & $28(14.5 \%)$ & $28(6.89 \%)$ & $13(6.73 \%)$ & $17(4.19 \%)$ & $14.35 \%$ \\
\hline 3 & & $\begin{array}{l}\text { Postmortem } \\
\text { brain } \\
\text { temporal } \\
\text { cortex } \\
\text { (GSE128380) }\end{array}$ & $46(10.55 \%)$ & $63(7.04 \%)$ & $33(7.56 \%)$ & $35(3.91 \%)$ & $13.31 \%$ \\
\hline 4 & \multirow{2}{*}{$\begin{array}{c}1.2 \\
\text { Pitt-Hopkins }\end{array}$} & $\begin{array}{c}\text { Tcf4-KO } \\
\text { (GSE79663) }\end{array}$ & $12(15 \%)$ & $1(2.86 \%)$ & $5(6.25 \%)$ & $0(0 \%)$ & $15.65 \%$ \\
\hline 5 & & $\begin{array}{c}\text { Tcf4-Het } \\
\text { (GSE79663) }\end{array}$ & $4(6.89 \%)$ & $0(0 \%)$ & $5(8.62 \%)$ & $0(0 \%)$ & $11.54 \%$ \\
\hline 6 & \multirow{5}{*}{$\begin{array}{l}\text { 1.3 Phelan- } \\
\text { McDermid }\end{array}$} & $\begin{array}{c}\text { PMS Female } \\
\text { 4w hiPSC } \\
\text { neurons } \\
\text { (GSE150429) }\end{array}$ & $2(2.89 \%)$ & $13(4.58 \%)$ & $2(2.89 \%)$ & $22(8.39 \%)$ & $11.78 \%$ \\
\hline 7 & & $\begin{array}{l}\text { PMS Female } \\
\text { 6w hiPSC } \\
\text { neu- } \\
\text { rons(GSE150429) }\end{array}$ & $2(1.92 \%)$ & $14(7.57 \%)$ & $3(2.88 \%)$ & $14(7.57 \%)$ & $11.42 \%$ \\
\hline 8 & & $\begin{array}{c}\text { PMS Female } \\
\text { 8w hiPSC } \\
\text { neurons } \\
\text { (GSE150429) }\end{array}$ & $1(5 \%)$ & $0(0 \%)$ & $0(0 \%)$ & $3(11.11 \%)$ & $8.5 \%$ \\
\hline 9 & & $\begin{array}{l}\text { PMS Male 6w } \\
\text { hiPSC } \\
\text { neurons } \\
\text { (GSE150429) }\end{array}$ & $21(8.36 \%)$ & $8(14.55 \%)$ & $11(4.38 \%)$ & $1(1.82 \%)$ & $13.4 \%$ \\
\hline 10 & & $\begin{array}{l}\text { PMS Male 8w } \\
\text { hiPSC } \\
\text { neurons } \\
\text { (GSE150429) }\end{array}$ & $14(5.34 \%)$ & $12(11.65 \%)$ & $12(4.58 \%)$ & $2(1.94 \%)$ & $10.96 \%$ \\
\hline
\end{tabular}


Table 2. Cont.

\begin{tabular}{|c|c|c|c|c|c|c|c|}
\hline & \multirow[b]{2}{*}{ Disorder } & \multirow[b]{2}{*}{ Model } & \multicolumn{2}{|c|}{ Calcium Target } & \multicolumn{2}{|c|}{ Calcium Regulating } & \multirow[b]{2}{*}{$\begin{array}{l}\text { All Calcium- } \\
\text { Related } \\
\text { DEG }\end{array}$} \\
\hline & & & $\begin{array}{c}\text { Down } \\
\text { Regulated } \\
\text { (\% from } \\
\text { Downregulated) }\end{array}$ & $\begin{array}{l}\mathrm{Up} \\
\text { Regulated } \\
\text { (\% from Up- } \\
\text { regulated) }\end{array}$ & $\begin{array}{c}\text { Down } \\
\text { Regulated } \\
\text { (\% from } \\
\text { Downregulated) }\end{array}$ & $\begin{array}{l}\quad \mathrm{Up} \\
\text { Regulated } \\
\text { (\% from Up- } \\
\text { regulated) }\end{array}$ & \\
\hline 11 & \multirow{3}{*}{$\begin{array}{l}\text { 1.4 Smith- } \\
\text { Magenis }\end{array}$} & $\begin{array}{l}\text { Rai1-CKO } \\
\text { Cortex } \\
\text { (GSE81206) }\end{array}$ & $0(0 \%)$ & $0(0 \%)$ & $0(0 \%)$ & $0(0 \%)$ & $0 \%$ \\
\hline 12 & & $\begin{array}{l}\text { Rai1-CKO } \\
\text { Hypothala- } \\
\text { mus } \\
\text { (GSE81206) }\end{array}$ & $0(0 \%)$ & $0(0 \%)$ & $0(0 \%)$ & $0(0 \%)$ & $0 \%$ \\
\hline 13 & & $\begin{array}{l}\text { Rai1-CKO } \\
\text { Striatum } \\
\text { (GSE81206) }\end{array}$ & $0(0 \%)$ & $0(0 \%)$ & $0(0 \%)$ & $0(0 \%)$ & $0 \%$ \\
\hline 14 & $\begin{array}{l}1.5 \text { Mowat- } \\
\text { Wilson }\end{array}$ & $\begin{array}{l}\text { Zeb2-cKO } \\
\text { cerebellum } \\
(\mathrm{P0}) \\
(\mathrm{GSE} 84098)\end{array}$ & $0(0 \%)$ & $0(0 \%)$ & $0(0 \%)$ & $0(0 \%)$ & $0 \%$ \\
\hline 15 & 2.1 Fragile $X$ & $\begin{array}{l}\text { hiPSC indel } \\
\text { exon3 FMR1 } \\
\text { (GSE117248) }\end{array}$ & $10(4.33 \%)$ & $15(7.28 \%)$ & $7(3.03 \%)$ & $12(5.82 \%)$ & $10.07 \%$ \\
\hline 16 & $\begin{array}{l}2.2 \text { Kabuki } \\
\text { Syndrome }\end{array}$ & $\begin{array}{l}\text { brains of } \\
\text { neuron- } \\
\text { specific } \\
\text { Kdm6a } \\
\text { deficient } \\
\text { mice }\end{array}$ & $0(0 \%)$ & $0(0 \%)$ & $0(0 \%)$ & $0(0 \%)$ & $0 \%$ \\
\hline 17 & \multirow{2}{*}{$\begin{array}{l}\text { 2.3 Tuberous } \\
\text { Sclerosis }\end{array}$} & $\begin{array}{c}\text { human } \\
\text { neural stem } \\
\text { cells derived } \\
\text { from } \\
\text { embryonic } \\
\text { stem cells } \\
\text { TSC2 }^{+/-} \\
\text {(TSC2-Het) }\end{array}$ & $1(25 \%)$ & $1(16.67 \%)$ & $0(0 \%)$ & $0(0 \%)$ & $20 \%$ \\
\hline 18 & & $\begin{array}{c}\text { human } \\
\text { neural stem } \\
\text { cells derived } \\
\text { from } \\
\text { embryonic } \\
\text { stem cell } \\
\text { sTSC2 }^{-/-} \\
\text {(TSC2-KO) }\end{array}$ & $78(8.76 \%)$ & $56(6.59 \%)$ & $49(5.50 \%)$ & $35(4.12 \%)$ & $12.54 \%$ \\
\hline
\end{tabular}

To further examine whether AS-found calcium-target and calcium-regulating signatures are indicative of Rett syndrome, we utilized a publicly available human postmortem patient brain dataset. This dataset is an RNA sequencing generated from postmortem brain tissue samples of four female patients clinically diagnosed with Rett syndrome and four age-matched female donors (GSE128380) [25]. The etiology of two out of three patients is known and includes one patient with an MECP2 mutation c $473 \mathrm{C}>\mathrm{T}$ and another patient with the deletion of exon 1 of the MECP2 gene. The etiology of the third patient is not known. The dataset contains transcriptomes from two brain regions of each individual: 
temporal and cingulate cortices. Following the authors' finding of a significant $3^{\prime}$ bias in some of the samples, we excluded these samples from further analysis [25].

In both cingulate and temporal cortices of the Rett patients, the calcium-target and calcium-regulating signatures separated the Rett samples from healthy controls on the PC1-PC2 plane well (Figure 2C-F). Analyses of differentially expressed genes in both postmortem cingulate and temporal cortices of Rett syndrome patients revealed the enrichment of calcium-related gene ontology (GO) terms (Supplementary Figure S1C-F). In addition, we found that of all differentially expressed genes, $14.35 \%$ (86 genes) in the cingulate cortex and $13.31 \%$ (177 genes) in the temporal cortex were calcium-related (Table 2, Supplementary Tables S2-S3).

\subsubsection{Pitt-Hopkins (GSE79663)}

Another neurodevelopmental disorder with clinical presentation similar to Angelman syndrome is Pitt-Hopkins syndrome (PTHS). Similarly to AS, Pitt-Hopkins is associated with development delay, hypotonia and delays in motor development, severe language impairment, epilepsy, and autism [28]. PTHS is caused by haploinsufficiency of the TCF4 protein [29]. TCF4 is a transcription factor that binds the E-Box DNA element (5'-CANNTG-3') and affects chromatin remodeling and transcription through the recruitment of histone acetyltransferases. TCF4 has been shown to affect neurodevelopment and play an important role in cognition, being associated with both schizophrenia and autism-spectrum intellectual disability in addition to PTHS [28]. Calcium signaling has been shown to be disrupted in mouse models of Tcf4 haploinsufficiency [28].

In order to determine whether our AS-found calcium-target and calcium-regulating signatures are also classifiers for PTHS, we re-analyzed the publicly available RNA sequencing dataset of dorsal telencephalons of Tcf4-knockout, Tcf4-heterozygous and WT mice at P0 (immediately after birth) (GSE79663) [30]. Studying the telencephalons of these Tcf4-knockout and heterozygous mice gives an indication of molecular disruptions in the cerebral cortex after initial development as projection neurons are generated in the proliferative ventricular zone and the subventricular zone of the embryonic telencephalon [30].

PCA based on the previously identified AS signatures of calcium-target and calciumregulating genes revealed that these signature genes are also good classifiers of PTHS in both Tcf4-knockout and heterozygous mouse models (Figure 3). Unsupervised analysis of differentially expressed genes in telencephalons of Tcf4-KO compared to WT mice revealed the enrichment of the 'calcium' GO term (Supplementary Figure S2A,B). Utilizing the CaGeDB database, we found that $15.65 \%$ (18 genes) of all differentially expressed genes were calcium-related (Table 2, Supplementary Table S4).

Performing differential expression analysis on the RNA-seq data of Tcf4 heterozygous mice, we did not find any enrichment of the calcium-related GO terms (Supplementary Figure S2C,D). Nevertheless, $11.54 \%$ (9 genes) of all dysregulated genes were from the CaDeGB database of known calcium-associated genes (Table 2, Supplementary Table S5). 
A.

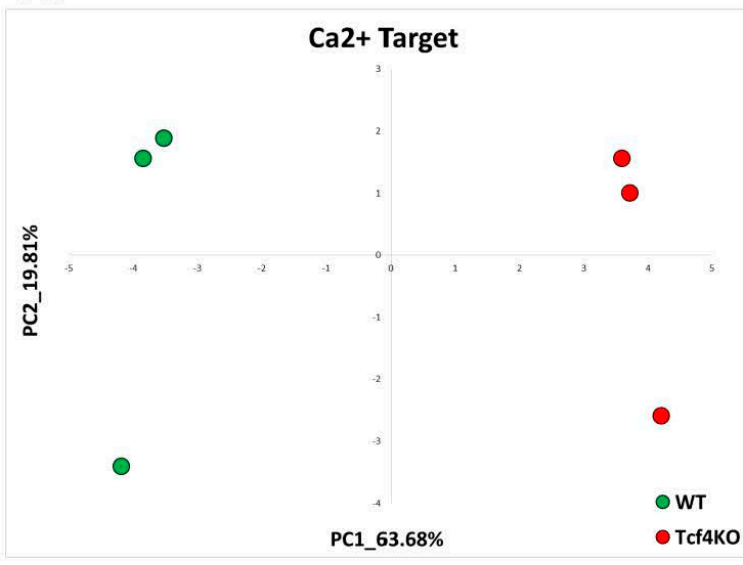

B.

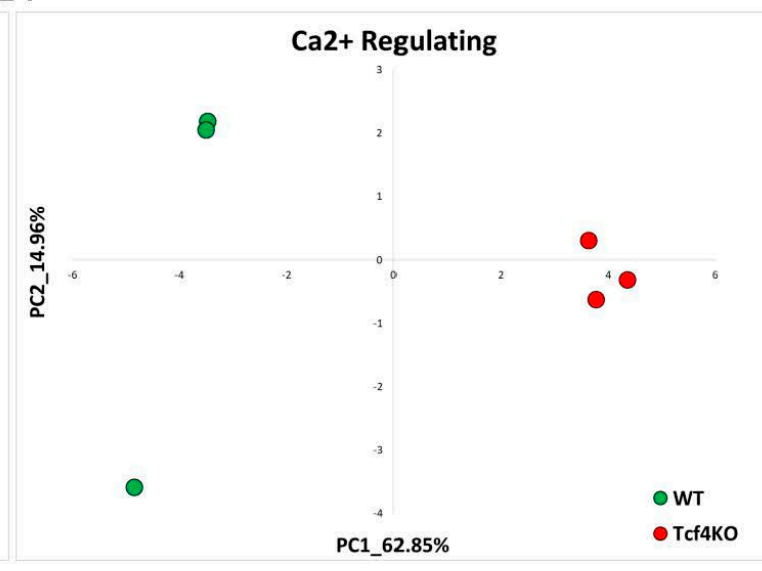

C.

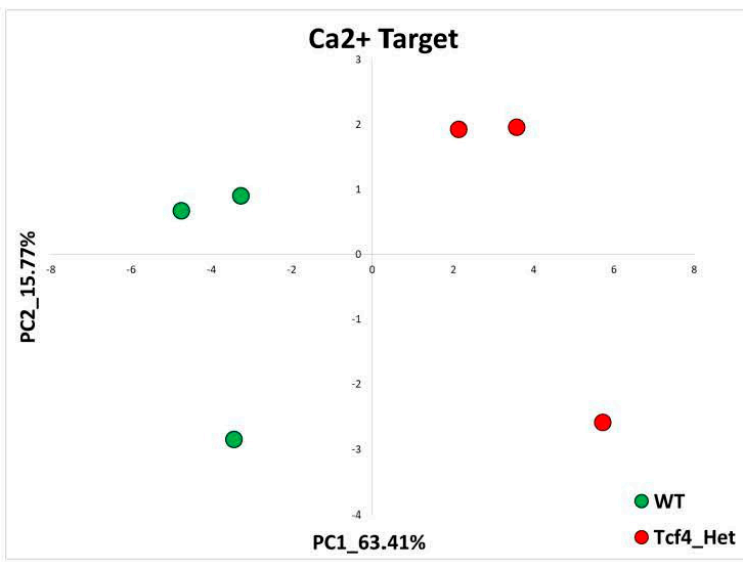

D.

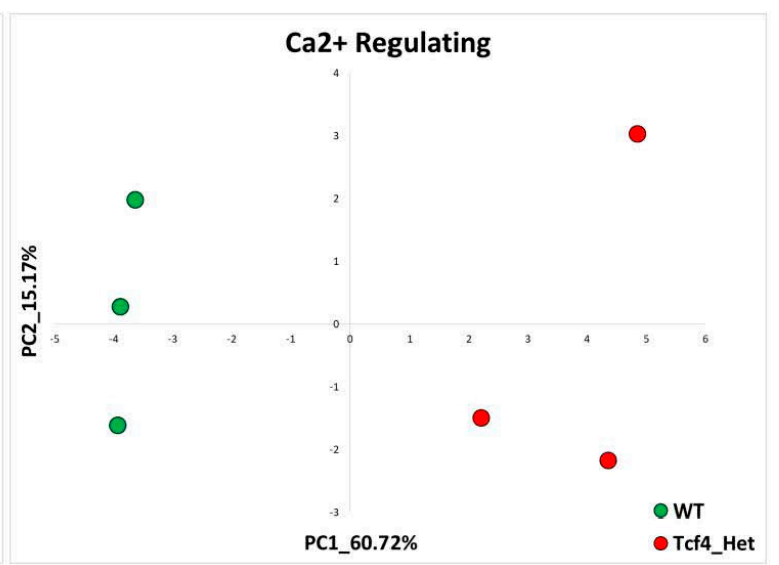

Figure 3. Pitt-Hopkins: ca-target and ca-regulating signatures. (A) PCA based on the expression of calcium-target signature genes in dorsal telencephalons of Tcf4 Knockout (Tcf4-KO) compared to control (WT) mice. The control samples are denoted in green, while the Tcf4 Knockout samples are in red. (B) PCA based on the expression of calcium-regulating signature genes in dorsal telencephalons of Tcf4 Knockout (Tcf4-KO) compared to control (WT) mice. The control samples are denoted in green, while the Tcf4 Knockout samples are in red. (C) PCA based on the expression of calcium-target signature genes in dorsal telencephalons of Tcf4 Heterozygous (Tcf4-Het) compared to control (WT) mice. The control samples are denoted in green, while the Tcf4 Knockout samples are in red. (D) PCA based on the expression of calcium-regulating signature genes in dorsal telencephalons of Tcf4 Heterozygous (Tcf4-Het) compared to control (WT) mice. The control samples are denoted in green, while the Tcf 4 Knockout samples are in red.

\subsubsection{Phelan-McDermid Syndrome (GSE150429)}

Another important mimic of AS is a chromosome 22q13.3 deletion (Phelan-McDermid) syndrome [31]. Phelan-McDermid syndrome (PMS) patients exhibit clinical symptoms similar to AS, including moderate-to-severe developmental delay with absent or minimal speech, neonatal hypotonia, feeding difficulties in infancy, and mouthing behaviors [31]. SHANK3 has been implicated as the critical gene in the chromosome 22q13.3 deletion syndrome; however, haploinsufficiency of other genes in the region influences the phenotypic expression and severity of the syndrome [32,33].

SHANK3 is a member of the Shank family of proteins that interact with various postsynaptic density (PSD) proteins through their functional domains [34]. Most notably, SHANKs bind to synapse-associated protein 90/postsynaptic density 95-associated protein, which, in turn, binds to PSD95 family proteins to form the PSD95/SAPAP/SHANK postsynaptic complex [35]. Although SHANK3 is not listed in the CaGeDB database of 
calcium-related genes, a recent study found SHANK3 directly binds CaMKII $\alpha$ and the L-type calcium channel and that this interaction is crucial for activating downstream CREB signaling [36].

To examine the applicability of the aforementioned AS calcium-target and calciumregulating gene signatures in PMS and to study the dysregulation of calcium signaling in PMS in general, we utilized the publicly available RNA sequencing dataset GSE150429 [37]. The RNA-seq data were generated from human-induced pluripotent stem cell-based model (hiPSC-neurons) of PMS by reprogramming peripheral blood samples from individuals with PMS $(n=7)$ and their unaffected siblings $(n=6)$ [37]. The etiology of six out of seven PMS patients included the deletion of chromosomal loci, including the SHANK3 gene. One patient had a frameshift mutation in the SHANK3 gene. For each participant, three hiPSC clones were generated and differentiated into forebrain neurons $(n=41)$ for three different time periods: 4 weeks, 6 weeks, and 8 weeks. Due to possible differences in calcium signaling between males and females [38], we separately studied the male and female hiPSC neurons differentiated at three different time points.

We found that at all points of neuronal development, the hiPSC neurons derived from female PMS patients were separated from hiPSC neurons derived from female healthy controls on the PC1-PC2 plane based on the expression of previously identified calciumtarget and calcium-regulating signature genes (Figure 4A-F). Interestingly, the separation of neurons derived from female PMS patients from hiPSC control samples was less evident at 8 weeks post-differentiation when using the expression of calcium target signature genes (Figure 4E).

In the male samples, we did not consider the hiPSC neurons at the 4-week passaging point because only one PMS sample was sequenced. Interestingly, in males, though the signatures separated between the PMS patients and the healthy controls on the PC1-PC2 plane, this separation was not as pronounced as in females (Figure $4 \mathrm{G}, \mathrm{H}, \mathrm{J}$ ). Moreover, the male PMS samples at 8 weeks post-differentiation using calcium target signature also showed a weaker separation of PMS samples from controls (Figure 4I).

Differential expression analysis did not reveal significantly enriched calcium-associated GO terms in either the female or male hiPSC-derived neurons (Supplementary Figure S3). Utilizing the $\mathrm{CaGeDB}$ database of calcium-related genes, we found that in female-derived 4 weeks post-differentiation hiPSC neurons, $11.78 \%$ (39 genes, Supplementary Table S6) of all dysregulated genes were calcium-related (Table 2). At 6 weeks post-differentiation female-derived hiPSC, we observed that $11.42 \%$ (33 genes, Supplementary Table S7) of all dysregulated genes were calcium-related. Interestingly, at 8 weeks post-differentiation of neurons derived from female PMS patients and healthy controls, we found considerably less differentially expressed genes than at 4 or 6 weeks post-differentiation. Of these dysregulated genes, $8.5 \%$ (four genes, Supplementary Table S8) were calcium-related. From male patient-derived hiPSCs, in the 6-week differentiating neurons, we observed $13.4 \%$ of all dysregulated genes were calcium-related (41 genes, Supplementary Table S9), and in the 8-week differentiating neurons, $10.96 \%$ (40 genes, Supplementary Table S10) of all dysregulated genes were calcium-related. 
A.

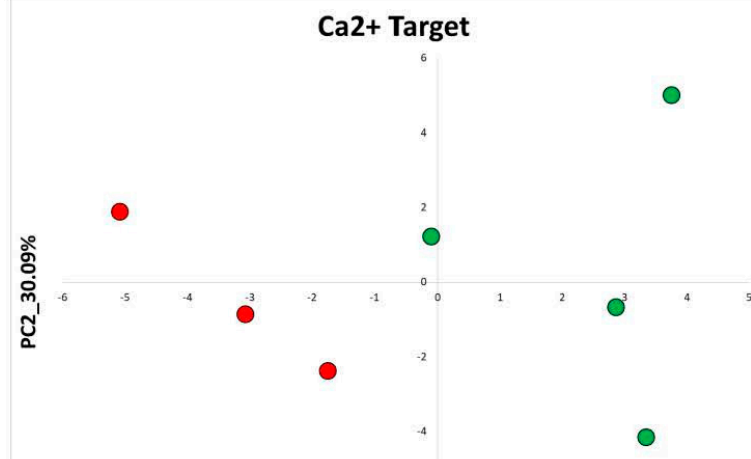

- CTL F 4w

- PMS F 4w
B.

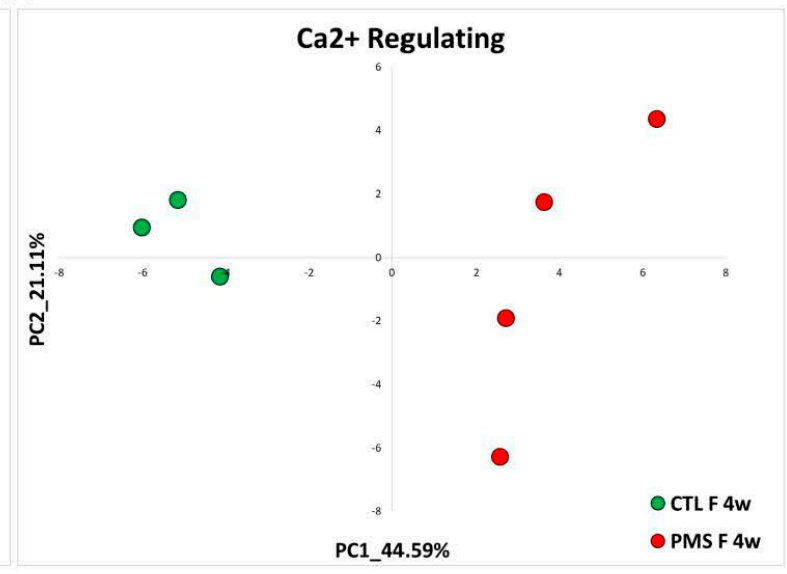

c.

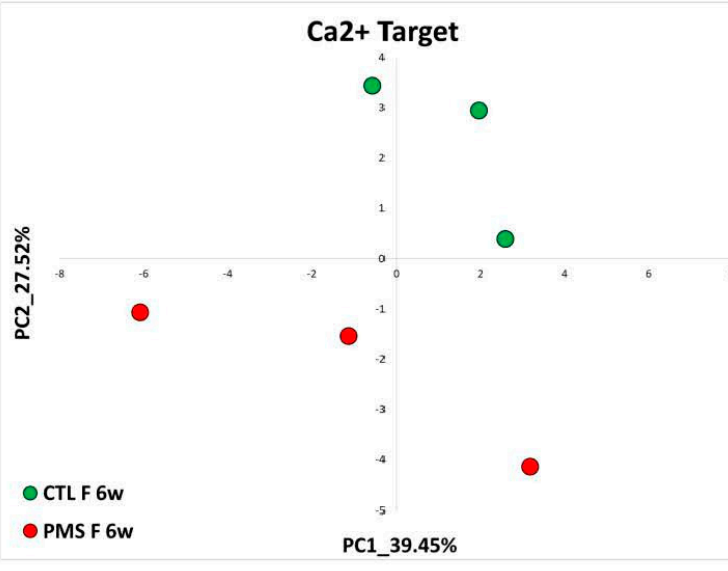

D.

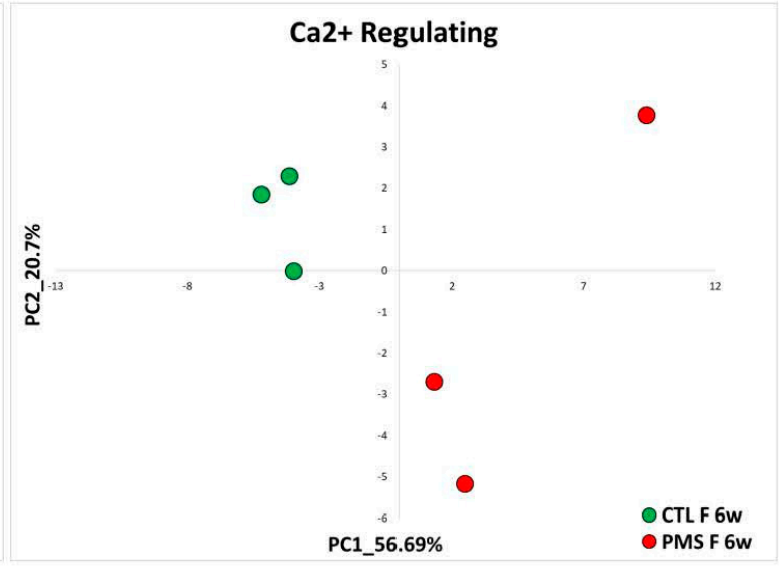

E.

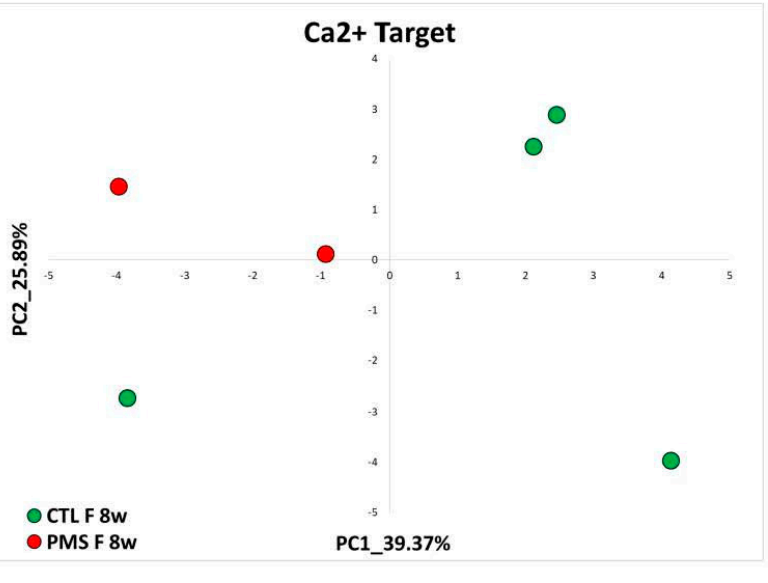

F.

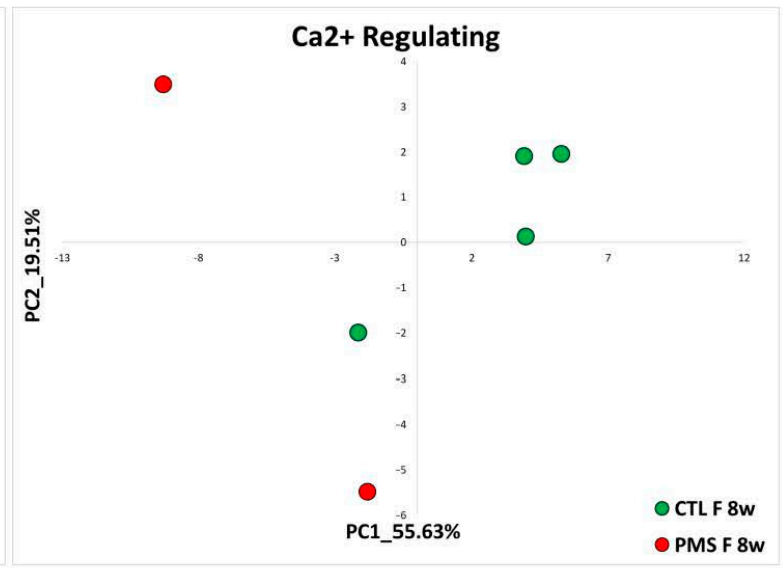

Figure 4. Cont. 
G.

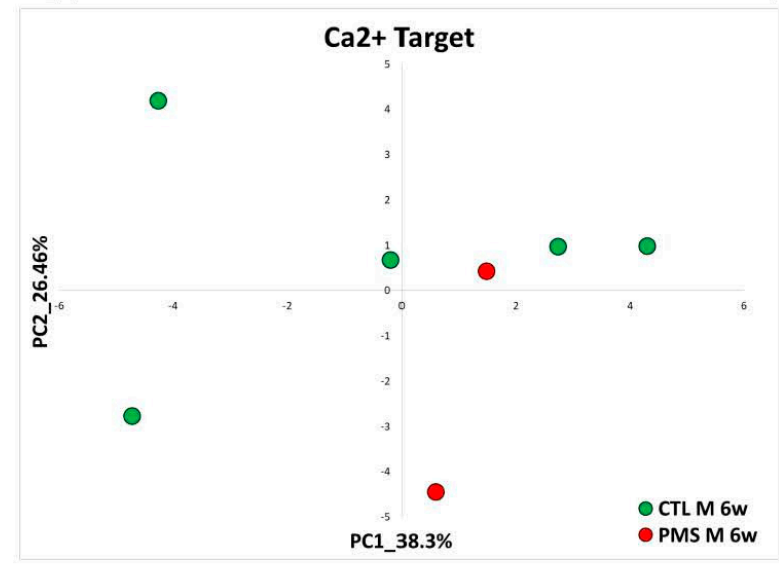

$\mathrm{H}$.

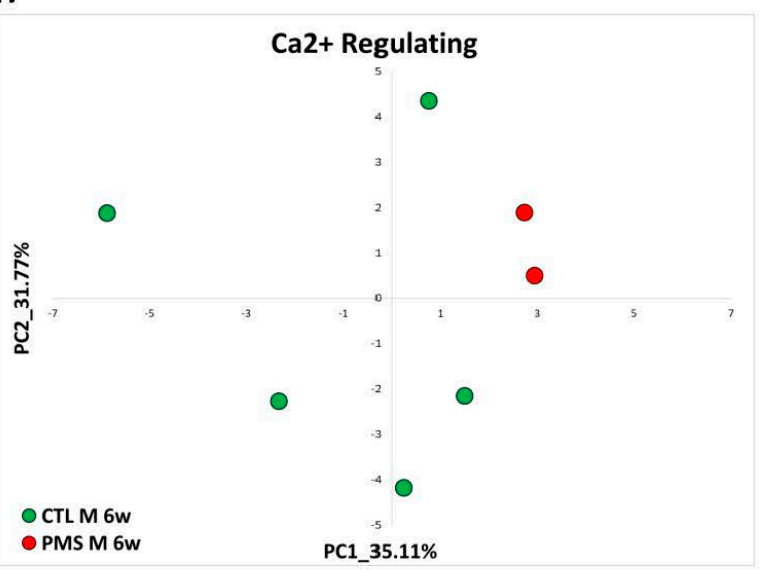

I.

J.

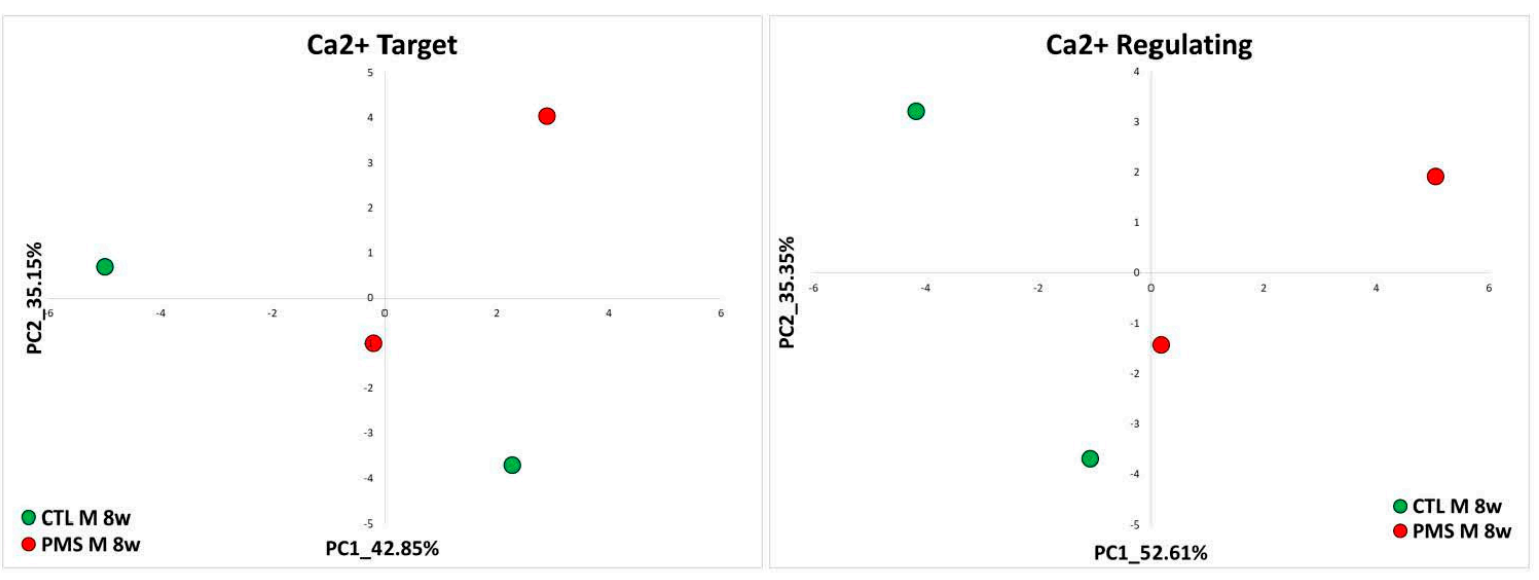

Figure 4. Phelan-McDermid Syndrome: ca-target and ca-regulating signatures (A) PCA based on the expression of calciumtarget signature genes in hiPSC-neurons differentiated for 4 weeks from female PMS patients and healthy controls. The control hi-PSCs are denoted in green, while the PMS hi-PSCs are in red. (B) PCA based on the expression of calciumregulating signature genes in hiPSC-neurons differentiated for 4 weeks from female PMS patients and healthy controls. The control hi-PSCs are denoted in green, while the PMS hi-PSCs are in red. (C) PCA based on the expression of calcium-target signature genes in hiPSC-neurons differentiated for 6 weeks from female PMS patients and healthy controls. The control hi-PSCs are denoted in green, while the PMS hi-PSCs are in red. (D) PCA based on the expression of calcium-regulating signature genes in hiPSC-neurons differentiated for 6 weeks from female PMS patients and healthy controls. The control hi-PSCs are denoted in green, while the PMS hi-PSCs are in red. (E) PCA based on the expression of calcium-target signature genes in hiPSC-neurons differentiated for 8 weeks from female PMS patients and healthy controls. The control hi-PSCs are denoted in green, while the PMS hi-PSCs are in red. (F) PCA based on the expression of calcium-regulating signature genes in hiPSC-neurons differentiated for 8 weeks from female PMS patients and healthy controls. The control hi-PSCs are denoted in green, while the PMS hi-PSCs are in red. (G) PCA based on the expression of calcium-target signature genes in hiPSC-neurons differentiated for 6 weeks from male PMS patients and healthy controls. The control hi-PSCs are denoted in green, while the PMS hi-PSCs are in red. (H) PCA based on the expression of calcium-regulating signature genes in hiPSC-neurons differentiated for 6 weeks from male PMS patients and healthy controls. The control hi-PSCs are denoted in green, while the PMS hi-PSCs are in red. (I) PCA based on the expression of calcium-target signature genes in hiPSC-neurons differentiated for 8 weeks from male PMS patients and healthy controls. The control hi-PSCs are denoted in green, while the PMS hi-PSCs are in red. (J) PCA based on the expression of calcium-regulating signature genes in hiPSC-neurons differentiated for 8 weeks from male PMS patients and healthy controls. The control hi-PSCs are denoted in green, while the PMS hi-PSCs are in red. 


\subsubsection{Smith-Magenis Syndrome (GSE81206)}

Smith-Magenis syndrome (SMS) is a neurobehavioral disorder caused by haploinsufficiency of the retinoic acid-induced 1 (RAI1) gene on chromosome 17p11.2 [39]. Unlike Angelman Syndrome that primarily affects the nervous system [40], SMS is a developmental disorder that affects multiple organ systems of the body [41]. SMS patients show a wide range of variability in symptoms. The majority of patients have mild-to-moderate intellectual disability, delayed speech and language skills, distinctive facial features, sleep disturbances, and behavioral problems [42].

Up to date, the RAI1 gene has been known as a transcriptional factor implicated in cell growth and cell cycle regulation, bone and skeletal development, lipid and glucose metabolisms, embryonic neurodevelopment and neuronal differentiation, behavioral functions, and circadian activity [39]; however, the exact mechanisms of transcript regulation by RAI1 have not been elucidated yet. In a recent study, Iwase and colleagues [43] have found that $R A I 1$ is an activity-dependent chromatin remodeler that suppresses synaptic upscaling triggered by activity silencing in the naive network.

Several mouse models of SMS exist; however, all of these models have severe limitations and do not represent the features of SMS patients well [44,45]. Most Rai1-null mice die in utero, and the few that survive exhibit craniofacial and skeletal abnormalities, motor dysfunction, and fear-learning deficits [44]. Rai1 heterozygous mice display some mild SMS-like symptoms, including obesity, circadian abnormalities, and characteristic craniofacial features [44]. In the herein study of calcium-related transcriptional changes in AS-like syndromes, we did not find a dataset of an SMS model in which Rai1 was deleted from all brain regions. Hence, we studied the publicly available RNA-seq dataset from three brain regions of conditional Rai1 knockdown and Rai1 $1^{\text {flox/flox }}$ control mice (GSE81206) [45]. In these mice, Nestin ${ }^{\mathrm{Cre}}$ was used to delete Rai1 from the cortex, Vglut2 ${ }^{\mathrm{Cre}}$ was used to delete Rai1 from the hypothalamus, and $\mathrm{Gad} 2{ }^{\mathrm{Cre}}$ was used to delete Rai1 from the striatum.

Nestin ${ }^{\mathrm{Cre}}$ Rai1 ${ }^{\mathrm{CKO}}$ mice exhibited postnatal lethality at an increasing frequency with age; thus, only young 3-week-old mice were used to delineate the effect of Rai1 on transcriptome changes in cortical brain tissue. Utilizing the previously found calcium-target and calcium-regulating signatures of AS, we evaluated whether conditional Rai1 knockdown in different brain regions disrupts calcium signaling. In the cortical brain region, the calcium-target signature genes separated the Nestin ${ }^{\mathrm{Cr}}$ Rai1 ${ }^{\mathrm{CKO}}$ samples from WT samples well, while the calcium-regulating signature genes were less efficient for Rai1 ${ }^{\mathrm{CKO}}$ separation (Figure 5A,B). Similarly, in the hypothalamus of Vglut $2^{\mathrm{Cre}}$ Rai1 ${ }^{\mathrm{CKO}}$ 8-week-old mice, calcium-target signature genes separated the Rai1 ${ }^{\mathrm{CKO}}$ mice from their controls, while again, the calcium-regulating signature genes did not (Figure 5C,D). In the striatum of 12-week-old mice, both calcium-target and calcium-regulating signatures separated the Rai1 ${ }^{\mathrm{CKO}}$ mice from the control WT mice (Figure 5E,F); however, the separation based on calcium-regulating genes was weaker than based on calcium-target genes. Nevertheless, both on the PC1-PC2 plane (Figure 5F) and on the PC1-PC3 plane (Figure 5G), the separation of WT and Rai1 ${ }^{\mathrm{CKO}}$ mice was evident.

Differential gene expression analysis of the above-mentioned datasets from three brain regions and three developmental stages of Rai1 ${ }^{\mathrm{CKO}}$ and WT mice revealed no genes that were differentially expressed in Rai1 ${ }^{\mathrm{CKO}}$ compared to WT control samples ( $p$-adjusted $<0.01$; absolute fold change $>2$ ). 
A.

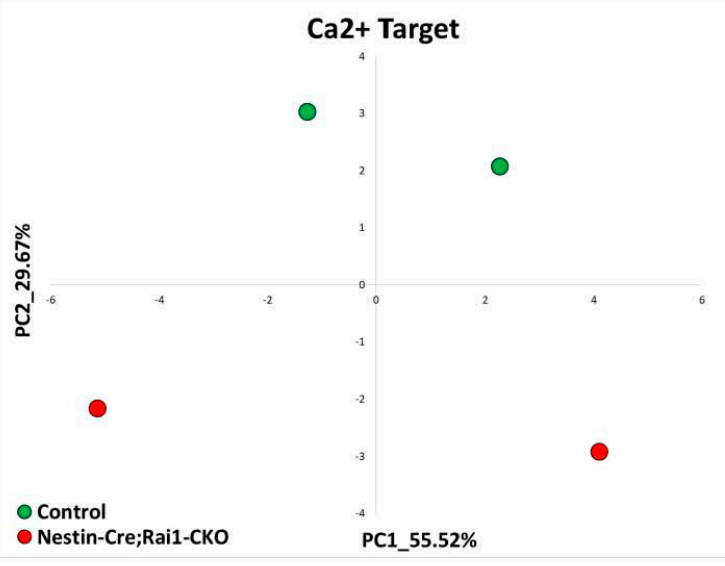

B.

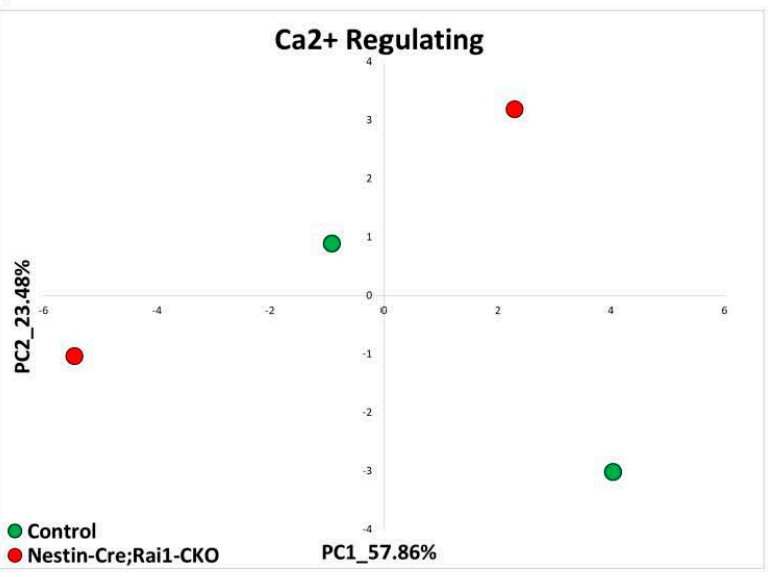

D.

c.

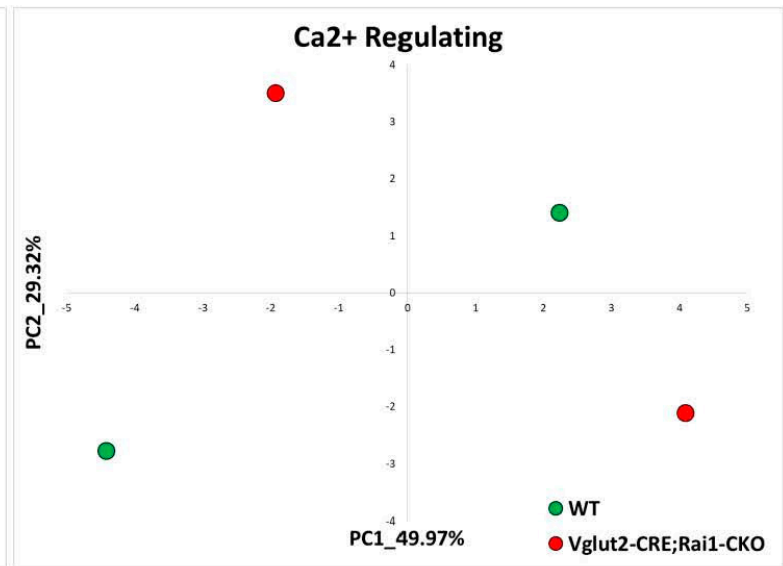

E.

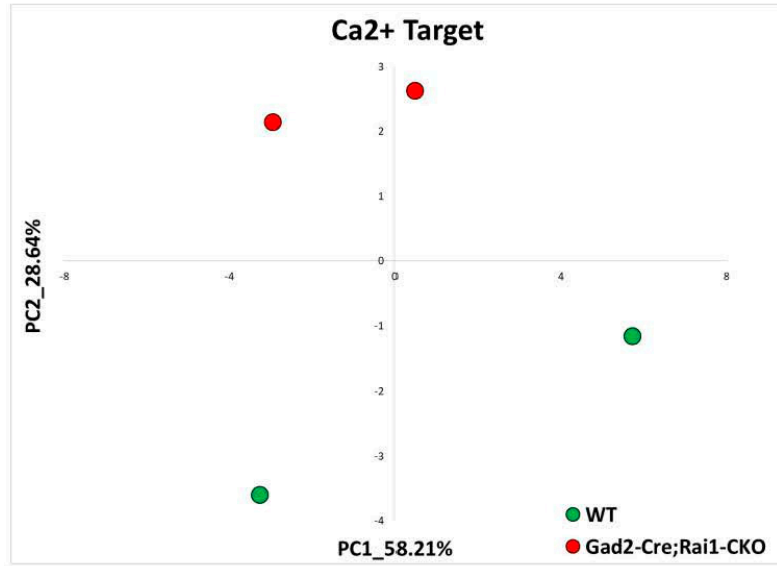

F.

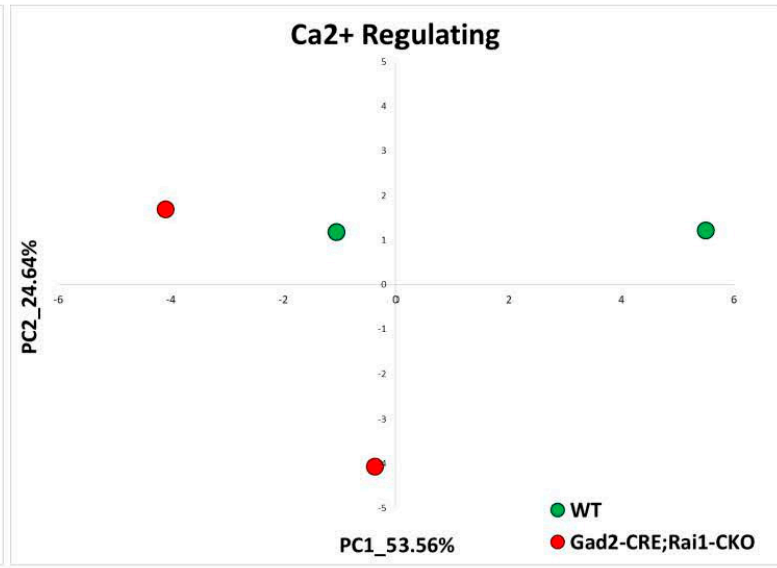

Figure 5. Cont. 


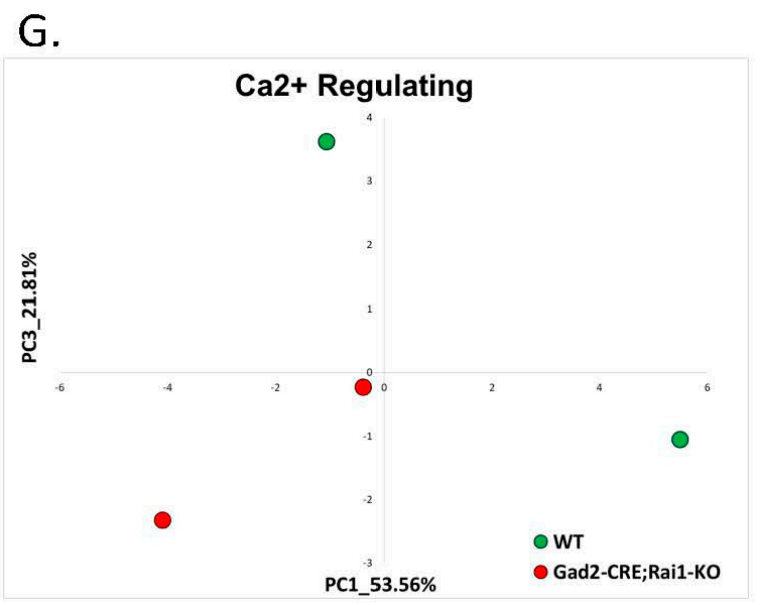

Figure 5. Smith-Magenis Syndrome: calcium target and calcium regulating signatures. (A) PCA based on the expression of calcium-target signature genes in the cortices of 3-week-old Nestin ${ }^{\mathrm{CRE}}$ Rai1 ${ }^{\mathrm{CKO}}$ (SMS model) mice compared to their controls. The control samples are denoted in green, while the SMS model samples are in red. (B) PCA based on the expression of calcium-regulating signature genes in the cortices of 3-week-old Nestin ${ }^{\mathrm{CRE}}{ }_{\text {Rai1 }}{ }^{\mathrm{CKO}}$ (SMS model) mice compared to their controls. The control samples are denoted in green, while the SMS model samples are in red. (C) PCA based on the expression of calcium-target signature genes in the hypothalamus of 8-week-old Vglut2 ${ }^{\mathrm{CRE}} \mathrm{Rai1}^{\mathrm{CKO}}$ (SMS model) mice compared to their controls. The control samples are denoted in green, while the SMS model samples are in red. (D) PCA based on the expression of calcium-regulating signature genes in the hypothalamus of 8-week-old Vglut2 ${ }^{\mathrm{CRE}} \mathrm{Rai1}^{\mathrm{CKO}}$ (SMS model) mice compared to their controls. The control samples are denoted in green, while the SMS model samples are in red. (E) PCA based on the expression of calcium-target signature genes in the striatum of 12 -week-old Gad2 ${ }^{\mathrm{CRE}} \mathrm{Rai1}^{\mathrm{CKO}}$ (SMS model) mice compared to their controls. The control samples are denoted in green, while the SMS model samples are in red. (F) PCA based on the expression of calcium-regulating signature genes in the striatum of 12 -week-old Gad2 ${ }^{\mathrm{CRE}}$ Rai1 ${ }^{\mathrm{CKO}}$ (SMS model) mice compared to their controls. The separation of samples on the PC1-PC2 plane. The control samples are denoted in green, while the SMS model samples are in red. (G) PCA based on the expression of calcium-regulating signature genes in the striatum of 12-week-old Gad2 ${ }^{\mathrm{CRE}} \mathrm{Rai1}^{\mathrm{CKO}}$ (SMS model) mice compared to their controls. The separation of samples on the PC1-PC3 plane. The control samples are denoted in green, while the SMS model samples are in red

\subsubsection{Mowat-Wilson Syndrome (GSE84098)}

Another single gene syndrome, which is sometimes included in the Angelman-like group of syndromes, is Mowat-Wilson Syndrome (MOWS). Mowat-Wilson syndrome is characterized by moderate-to-severe intellectual disability, distinctive facial appearance, and epilepsy. Unlike Angelman syndrome patients, patients with MOWS develop multiple congenital anomalies, including congenital heart disease, agenesis of the corpus callosum, and eye defects [46].

Mowat-Wilson is caused by deleterious de novo heterozygous variations in the Zeb2 gene that usually cause haploinsufficiency of the Zeb2 protein. The Zeb2 protein, also known as ZFHX1B (zinc finger homeobox 1B) or SIP1 (Smad-interacting protein 1) [47], is a member of the ZEB family of zinc finger transcription factors, which are essential during normal embryonic development [48]. Earlier, it has been shown that Zeb2 regulated calcium signaling pathways at least in the heart [49] and during cerebellar development at P0 [50].

To investigate whether the previously identified Angelman Syndrome derived signatures can also be useful in identifying Mowat-Wilson Syndrome, we utilized publicly available RNA-seq data from the cerebellum of Zeb2-cKO (deletion of the Zeb2 gene in cerebellar neural progenitors) mice right after birth (P0) and their WT controls (GSE84098) [50]. Zeb2-cKO mice were bred from Zeb2-floxed mice with a human GFAP promoter-driven Cre (hGFAP-Cre), which is expressed in radial glia or neural stem/progenitors that can give rise to the majority of the cell types, including Bergmann glia, astrocytes, oligodendrocytes, and granule neurons in the cerebellum. We found that based on both calciumtarget and calcium-regulating signatures, Zeb2-cKO cerebella were separated from WT controls (Figure 6). Zeb2-cKO mice were clearly separated from controls based on calcium- 
regulating signature genes (Figure 6C). The calcium-target signature genes also separated Zeb2-cKO mice from controls on both the PC1-PC2 plane (Figure 6A) and the PC1-PC3 plane (Figure 6B).

A.

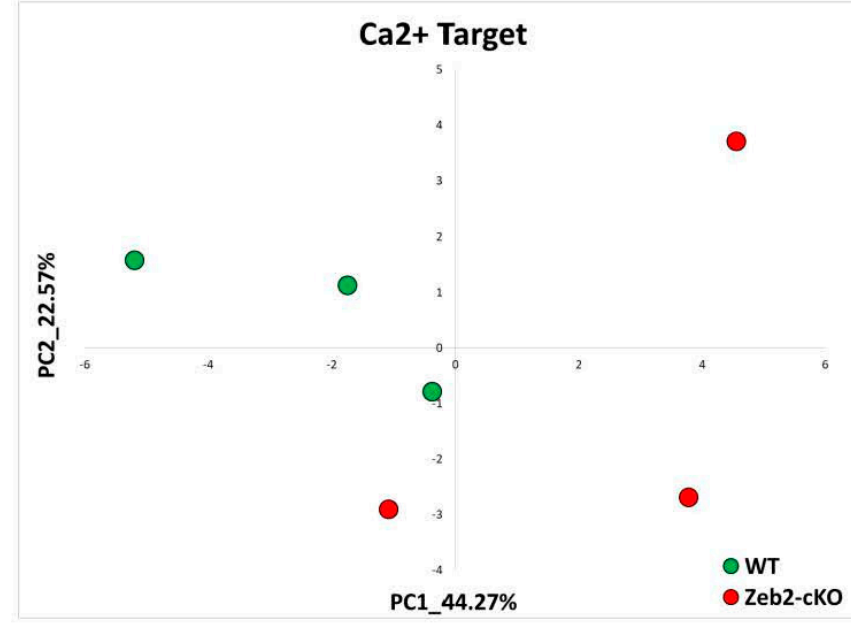

B.

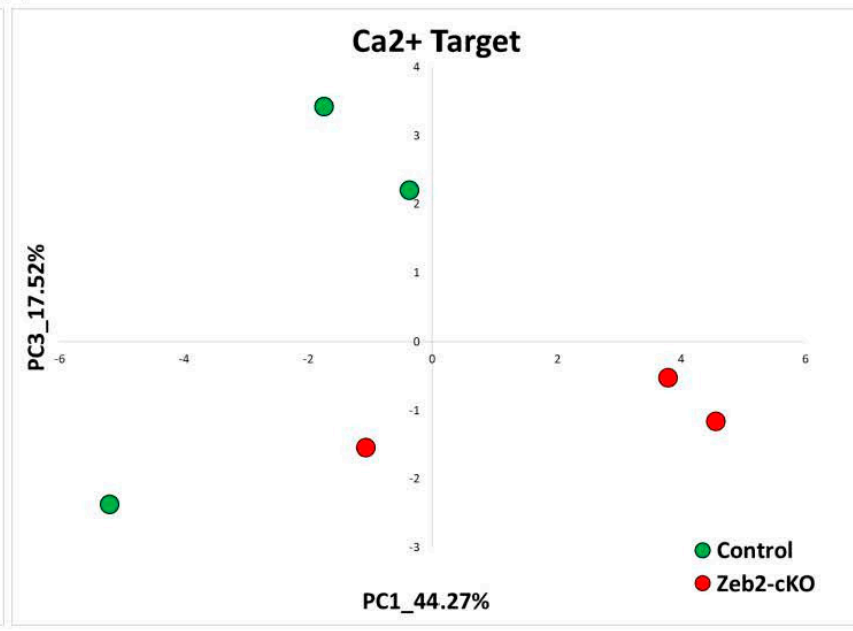

C.

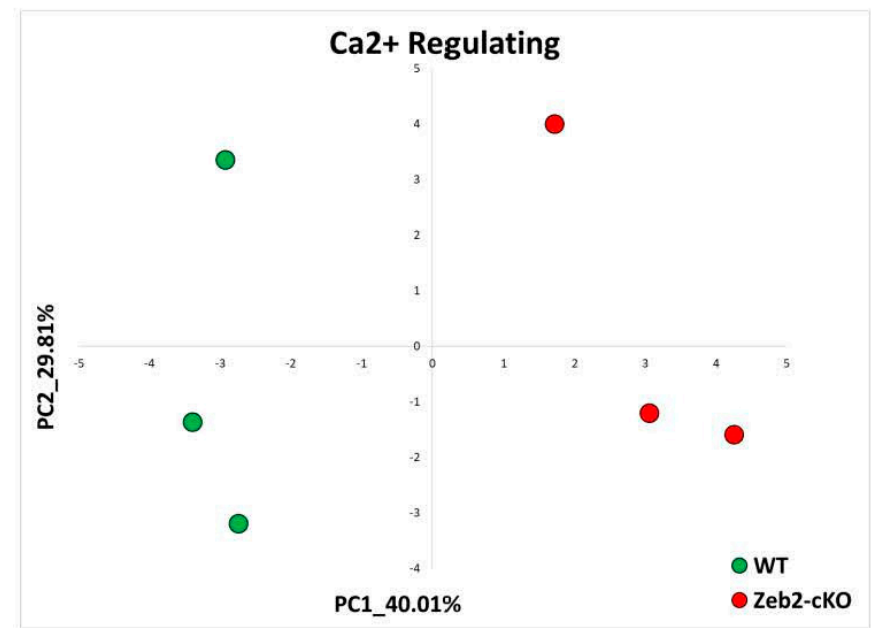

Figure 6. Mowat-Wilson Syndrome: calcium target and calcium regulating signatures. (A) PCA based on the expression of calcium-target signature genes in the cerebellum of Zeb2-cKO (deletion of the Zeb2 gene in cerebellar neural progenitors) mice right after birth (P0) and their wild-type (WT) controls. The separation of samples on the PC1-PC2 plane. The control samples are denoted in green, while the Zeb2-cKO samples are in red. (B) PCA based on the expression of calcium-target signature genes in the cerebellum of Zeb2-cKO (deletion of the Zeb2 gene in cerebellar neural progenitors) mice right after birth (P0) and their wild-type (WT) controls. The separation of samples on the PC1-PC3 plane. The control samples are denoted in green, while the Zeb2-cKO samples are in red. (C) PCA based on the expression of calcium-regulating signature genes in the cerebellum of Zeb2-cKO (deletion of the Zeb2 gene in cerebellar neural progenitors) mice right after birth (P0) and their wild-type (WT) controls. The control samples are denoted in green, while the Zeb2-cKO samples are in red.

Differential gene expression analysis did not reveal significantly enriched calciumassociated processes (Supplementary Figure S4A,B). In addition, none of the known calcium-related genes from the $\mathrm{CaGeDB}$ database were differentially expressed in Zeb2cKO mice compared to controls. Nevertheless, earlier analysis by the authors of the dataset showed enrichment of calcium-signaling pathways by upregulated genes in Zeb2-cKO samples [50]. 


\subsection{Non-AS Like Syndromes}

In order to evaluate whether the previously found calcium-target and calcium-regulating signatures are indicators of an AS-like phenotype and not general predictors of neurodevelopmental disorders, we studied several syndromes that are not considered AS-like based on their phenotypic presentation. These syndromes include Fragile X Syndrome, Kabuki Syndrome, and Tuberous Sclerosis. In all of these syndromes, we found that the calcium-target and calcium-regulating signatures found in AS were not good classifiers of these disorders.

\subsubsection{Fragile X Syndrome (GSE117248)}

Like any neurodevelopmental disorder, Fragile $X$ syndrome entails some similarities with AS, such as intellectual disability, speech impairment, abnormal social and emotional interactions, and autism [51,52]. Nonetheless, there are quite a few differences between the two syndromes. FXS patients have a lower percentage of epileptiform activity $(\sim 10 \%-20 \%)$ [53], and they do not have the absence of speech despite having speech impairments. Moreover, Fragile X Syndrome is not limited to Central Nervous System (CNS) and impacts the whole body, including heart disorders, connective tissue dysregulation, gastrointestinal disorders, and mood disorders [54].

Nearly all cases of FXS result from the expansion of CGG repeats in the $5^{\prime}$ UTR region of the X-linked fragile $\mathrm{X}$ mental retardation 1 gene (FMR1) [52]. The expansion of the CGG triplet to more than 200 copies leads to DNA methylation and thus to transcriptional inactivation and the loss of the FMR1 gene product known as FMRP (fragile $\mathrm{X}$ mental retardation protein) [52]. FMRP is an mRNA binding protein that is involved in activity-dependent translation. FMRP is primarily a translational inhibitor; however, changes in transcription or in RNA stability may also lead to increased protein levels [55]. Recently, it has been shown that FMRP regulates post-transcriptional modifications as well as chromatin organization and modifications $[55,56]$.

To elucidate whether previously found AS calcium-target and calcium-regulating signatures are valid for classifying the non-AS-like syndrome FXS, we utilized a publicly available RNA-seq dataset generated from an isogenic human pluripotent stem cell model (GSE117248) [57]. The neurons were differentiated from human neural progenitor cellderived hiPSCs, with a midbrain-patterning differentiation protocol using CRISPR/Cas9 to introduce indels in exon 3 of FMR1, resulting in a complete loss of FMRP expression.

Unlike most AS-like syndrome models, PCA based on the above-mentioned AS signatures of calcium-target and calcium-regulating genes did not separate the FXS-model neurons from the control neurons (Figure 7A,B).

Nonetheless, differential gene expression analysis showed that the 'calcium-binding' GO term was enriched by dysregulated genes in FXS-model neurons but not other calciumrelated GO terms (Supplementary Figure S5A,B). Utilizing the CaGeDB database of calciumrelated genes, we found that in FXS-model neurons, 10.07\% (44 genes, Supplementary Table S11) of all dysregulated genes were calcium-related (Table 2). 
A.

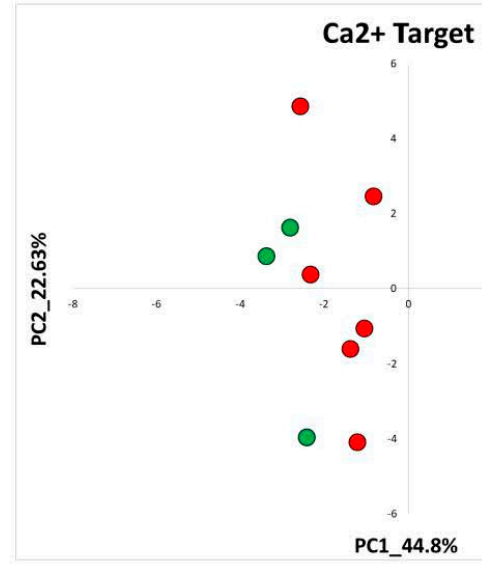

B.

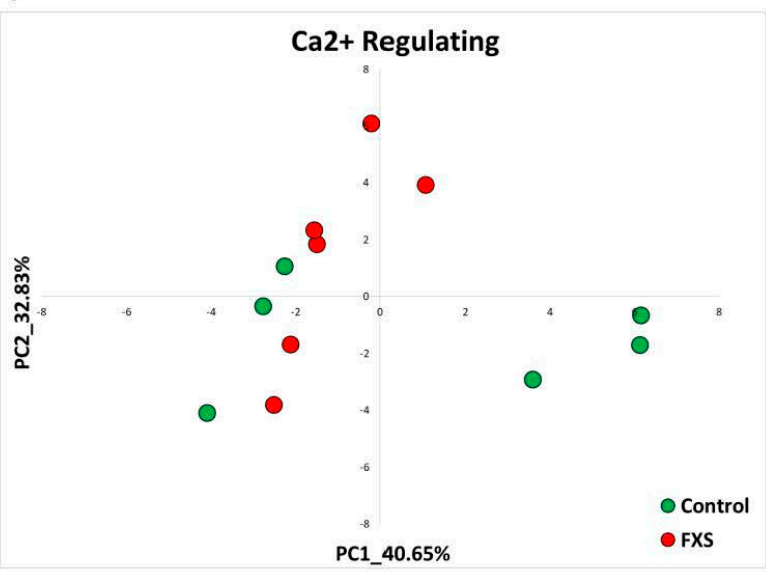

Figure 7. Fragile $X$ Syndrome: calcium-target and calcium-regulating signatures. (A) PCA based on the expression of calcium-target signature genes in hiPSCs derived from FXS patients compared to control hiPSCs. The control samples are denoted in green, while the FXS samples are in red. (B) PCA based on the expression of calcium-regulating signature genes in hiPSCs derived from FXS patients compared to control hiPSCs. The control samples are denoted in green, while the FXS samples are in red.

\subsubsection{Kabuki Syndrome (GSE81251)}

Kabuki Syndrome (KS) is an additional neurodevelopmental disorder that has a different clinical presentation from AS and is considered a non-AS-like syndrome. KS is characterized by distinct facial dimorphism, growth retardation, psychomotor developmental delay, and a wide spectrum of other manifestations affecting various body systems [58]. KS is a result of a loss of function of either KMT2D or KDM6A proteins. Both of these proteins are histone modifiers that contribute to the opening of chromatin for gene transcription. KMT2D catalyzes the addition of methyl groups to lysine 4 of histone 3 (H3K4me1 and H3K4me3). Both H3K4me1 and H3K4me3 are marks associated with open chromatin; thus, the dysregulation of KMT2D leads to excessive gene transcription. KDM6A also participates in chromatin opening for transcription by removing H3K27me3, which is a mark of closed chromatin [59]. Both genes play a critical role in early vertebrate development, and their reduced expression results in craniofacial, cardiac, and brain abnormalities [58-60].

We utilized publicly available RNA-seq data from brains of a neuron-specific Kdm6adeficient mouse model (GSE81251) to identify whether the aforementioned calcium-target and calcium-regulating signatures could classify the non-AS-like Kabuki Syndrome.

As with the previous non-AS-like syndrome FXS and contrary to the AS-like syndrome models, PCA based on the calcium-target and calcium-regulating gene signatures did not separate the Kabuki mouse model from their control mice littermates on the PC1-PC2 plane (Figure 8A,B). 
A.

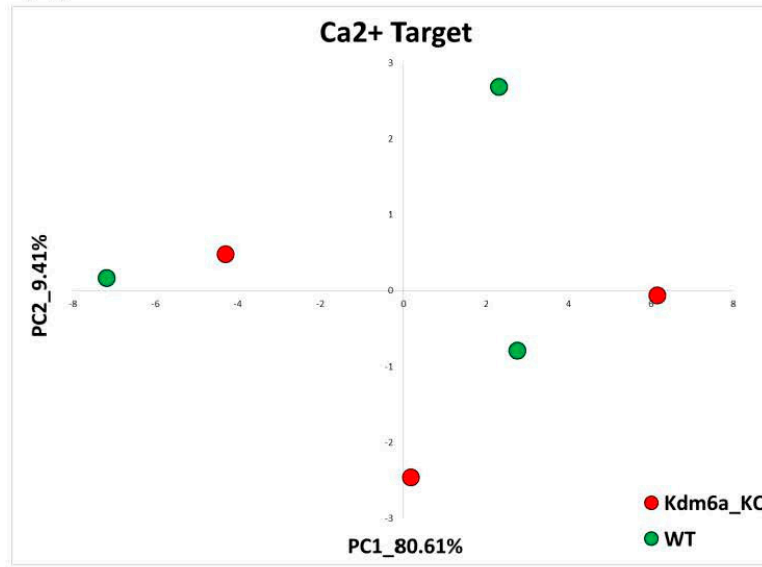

B.

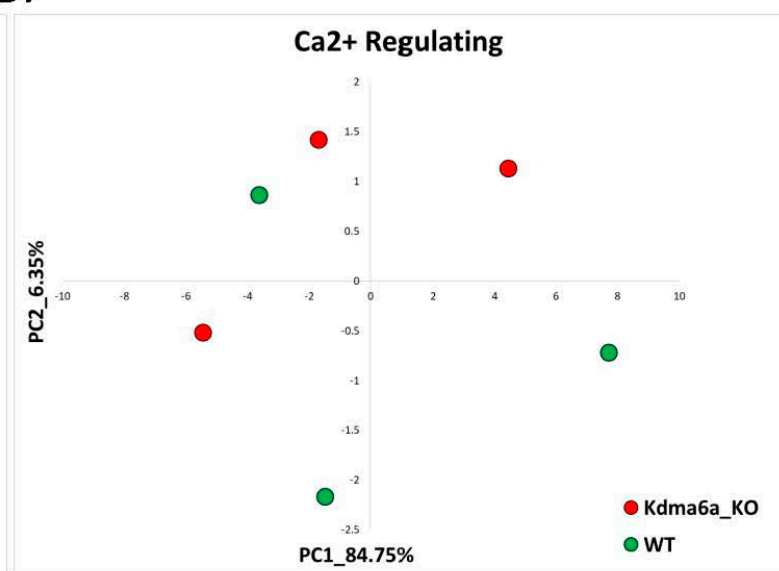

Figure 8. Kabuki Syndrome: calcium-target and calcium-regulating signatures. (A) PCA based on the expression of calcium-target signature genes in brain tissue of neuron-specific Kdm6a-deficient mice and their WT controls. The control samples are denoted in green, while the Kdm6a-KO samples are in red. (B) PCA based on the expression of calcium-regulating signature genes in brain tissue of neuron-specific Kdm6a-deficient mice and their WT controls. The control samples are denoted in green, while the Kdm6a-KO samples are in red. Differential gene expression analysis revealed no differentially expressed genes in this Kabuki mouse model. Nonetheless, when the threshold of significance was reduced to include only adjusted $p$-values $<0.01$ (without any threshold of fold change), the analysis of differentially expressed genes showed that 'Calcium' and 'Calcium-dependent membrane-targeting' GO terms were significantly enriched (Supplementary Figure S6A,B).

\subsubsection{Tuberous Sclerosis (GSE78959)}

Tuberous Sclerosis (TSC) is a genetic disorder that involves numerous tissues. Apart from the neurological deficits, patients also have heart, kidney, and skin lesions. The neurological symptoms include developmental delay or mental retardation, autism, behavioral problems, and seizures that occur in an overwhelming percentage of TSC patients [61,62].

The two genes that are involved in the etiology of TSC are TSC1 and TSC2, which encode the proteins hamartin and tuberin, respectively. Inactivating mutations in any of these two genes impair the function of the TSC protein complex. This complex acts as an inhibitor of the Ras homolog enriched in brain (Rheb) and mammalian Target of Rapamycin (mTOR) complex 1 (mTORC1) signaling pathway, which controls almost every aspect of cellular metabolism [61-63].

We utilized a publicly available dataset generated from human neural stem cells derived from embryonic stem cells that have a deletion of the TSC2 gene (GSE78959) [64]. The dataset includes three cell lines: TSC2 ${ }^{+/+}$(wild-type), TSC2 $^{+/-}$(TSC2-Het), and TSC2 ${ }^{-/-}$(TSC2-KO), which were independently generated from wild-type human embryonic stem cells.

We found that for the TSC2 $2^{+/}$cell line, PCA analyses based on calcium-target and calcium-regulating signatures of AS were not effective in identifying TCS model samples from wild-type controls (Figure 9A,B). Additionally, the differential gene expression analysis did not reveal enriched calcium-associated GO terms (Supplementary Figure S7A,B). Utilizing the CaGeDB database of calcium-related genes, we found that in $\mathrm{TSC}^{+/-}$cell line, $20 \%$ (two genes, Supplementary Table S12) of all dysregulated genes were calcium-related (Table 2).

Interestingly, our previously identified calcium-target and calcium-regulating gene signatures were good classifiers of the cell line with a total deletion of the TSC2 gene (TSC2 $^{-{ }^{-}}$) (Figure 9C,D). It is important to note that TSC patients have a heterozygous deletion and not a complete deletion of either TSC1 or TSC2 genes [65]. In addition, unsupervised analysis of differentially expressed genes showed that calcium-associated molecular pathways were enriched by genes dysregulated in TSC2 ${ }^{-/}$cell lines (Supplementary Figure S7C,D). Based on the CaGeDB database of calcium-related genes, we found 
that in $\mathrm{TSC}^{-/-}$cell line, $12.54 \%$ (218 genes, Supplementary Table S13) of all dysregulated genes were calcium-related (Table 2).

A.

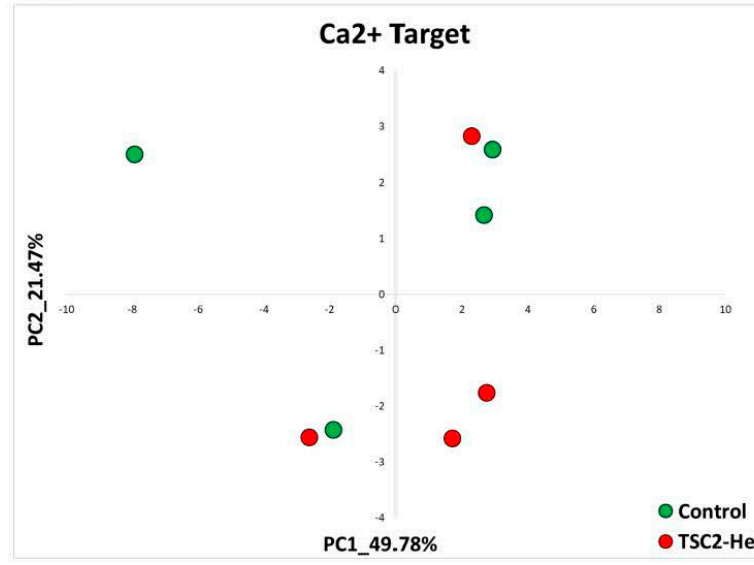

B.

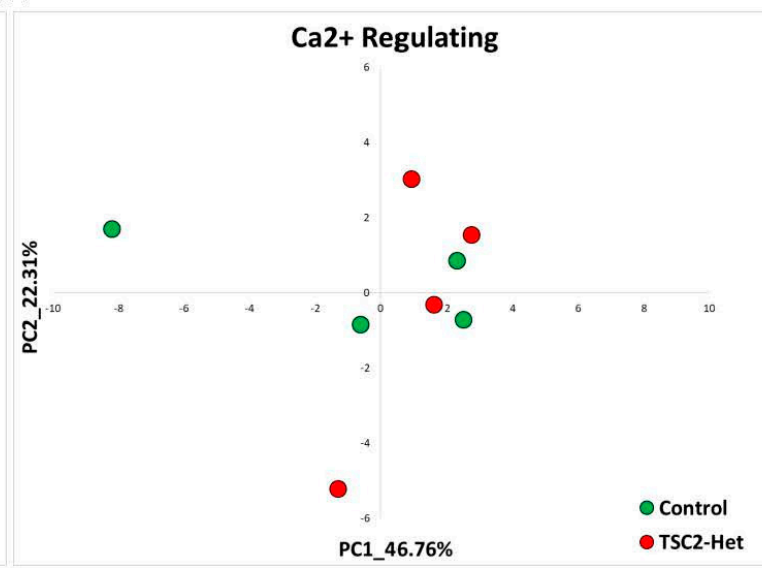

C.

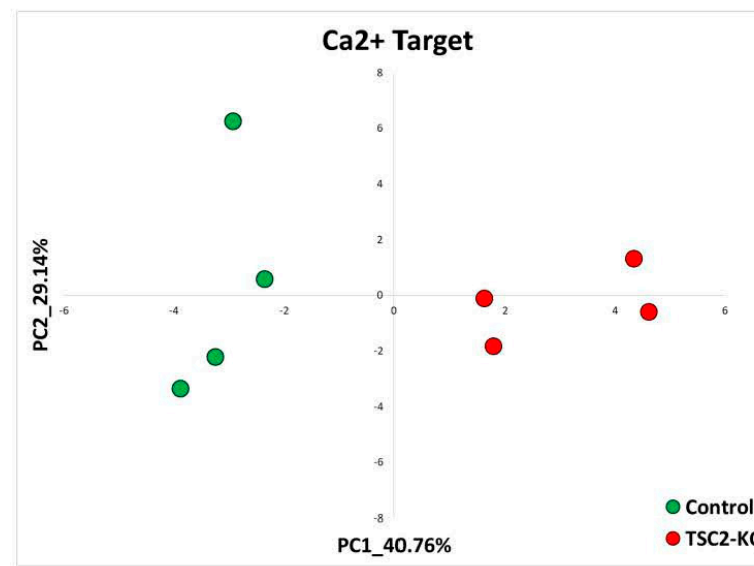

D.

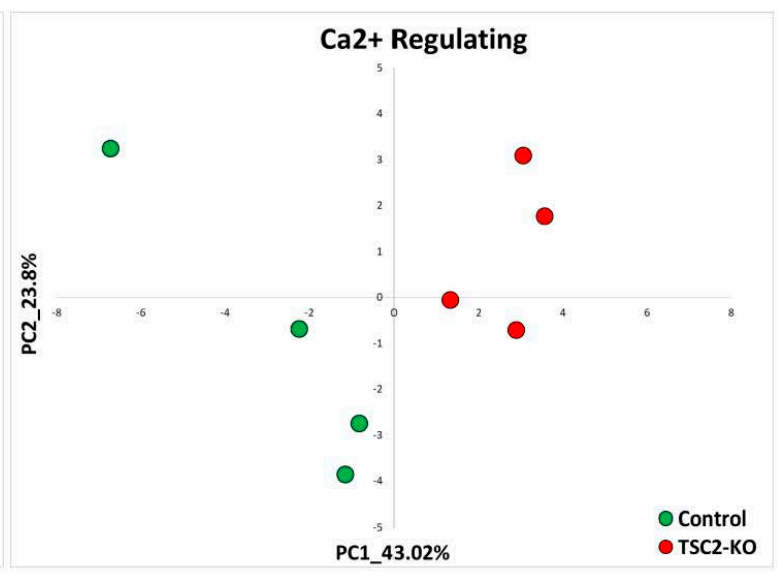

Figure 9. Tuberous sclerosis: calcium-target and calcium-regulating signatures. (A) PCA based on the expression of calciumtarget signature genes in the TSC2 ${ }^{+/}$hESCs cell line (TCS2-Het) compared to the control hESCs cell line. The control samples are denoted in green, while the TCS2-Het samples are in red. (B) PCA based on the expression of calcium-regulating signature genes in the TSC2 ${ }^{+/}$hESCs cell line (TCS2-Het) compared to the control hESCs cell line. The control samples are denoted in green, while the TCS2-Het samples are in red. (C) PCA based on the expression of calcium-target signature genes in the TSC2 ${ }^{-/}$hESCs cell line (TCS2-KO) compared to the control hESCs cell line. The control samples are denoted in green, while the TCS2-KO samples are in red. (D) PCA based on the expression of calcium-regulating signature genes in the TSC2 $2^{-/}$hESCs cell line (TCS2-KO) compared to the control hESCs cell line. The control samples are denoted in green, while the TCS2-KO samples are in red.

\section{Discussion}

In a previous study, we found signatures of calcium-target and calcium-regulating genes that perfectly distinguished AS from their controls in different mouse and human models for AS [14]. In a further attempt to investigate the uniqueness of these gene signatures for AS, we herein evaluated whether the calcium-dependent signatures are valid for other neurodevelopmental syndromes. Our initial hypothesis was that these gene signatures were unique for AS. For this aim, we collected RNA-seq datasets of a number of neurodevelopmental syndromes and re-analyzed the transcriptome datasets in light of the calcium-related genes and gene signatures. Surprisingly, we found that calcium-target and calcium-regulating gene signatures were also good classifiers of AS-like 
syndromes. However, these signatures could not differentiate the neurodevelopmental syndromes with a different clinical presentation from AS and which are not considered AS-like well. This was even more fascinating due to the fact that many of the non-AS-like syndromes had multiple dysregulated calcium-associated genes, as shown by the analyses of differentially expressed genes and their GO term enrichment. Taken together, it is unusual to find that distinctly identified calcium-related gene signatures, which were found using a machine learning approach in several AS models [14], were also able to segregate between other genetic AS-like disorders and their controls. It was even more surprising to find that the calcium-target and calcium-regulating gene signatures were not able to classify neurodevelopmental disorders that do not have a similar clinical presentation to AS. The notion that bioinformatics analyses reflect a general clinical impression towards the categorization of syndromes is quite striking.

Nonetheless, despite the finding that classification based on calcium-related gene signatures was able to classify five AS-like syndromes but failed to do so with three nonAS-like syndromes, it is important to emphasize that there are plenty more non-AS-like syndromes, and we did not examine this bioinformatics procedure on all syndromes. We chose the ones that we could find a good quality transcriptome with a reasonable disease cellular model. Moreover, the clinical categorization to AS-like and non-AS-like is quite illusive, and it is difficult to clearly delineate between these two categories based on clinical similarity and dissimilarity with AS. Most neurodevelopmental syndromes share many common features, such as intellectual disability, developmental delays, susceptibility for epilepsy, autistic behavior features, and others. Because of that, it would not be surprising if, in the future, this classification would fail for a specific syndrome in a particular model.

The full meaning of the aforementioned findings is not yet clear, but it puts forward some ideas. For example, it emphasizes the importance of assimilating clinical observations into scientific thinking about the pathophysiological mechanisms of various disorders. In particular, it suggests a specific calcium disruption in AS-like syndromes and points towards a shared final common pathway between these syndromes, thus leading to a similar phenotype. In addition, our findings show that machine-learning approaches applied to available molecular datasets might be useful in the future for the classifications of various disorders. Additionally, the question of whether such findings carry some therapeutic significance is also intriguing. Since if calcium signaling is an important aspect of all AS-like syndromes, then there is a possibility that a pharmacological intervention that will normalize calcium signaling would be beneficial in treating at least some aspects of these disorders.

\section{Materials and Methods}

Raw expression matrices were downloaded from ncbi GEO collection (https: / /www. ncbi.nlm.nih.gov/gds/, 11 September 2021). All datasets used in the current study are presented in Table 1. The normalization of raw expression matrices for further downstream analyses was performed with the DeSeq2 algorithm [17].

Two lists of calcium-target and calcium-regulating genes (Tables 3 and 4) that were identified as signatures of AS in our previous study [14] were used to evaluate whether these signatures can be used for other AS-like and non-AS-like neurodevelopmental syndromes. Principle Component Analysis (PCA) [18] of the expression matrices of calciumtarget and calcium-regulating signature lists in each dataset was performed in $\mathrm{R}$ using the 'prcomp ()$^{\prime}$ function. 
Table 3. Calcium-target signature genes identified in AS model mice.

\begin{tabular}{|c|c|c|}
\hline GeneSymbol & Ensemble_Mouse & Ensemble_Human \\
\hline Syt11 & ENSMUSG00000068923 & ENSG00000132718 \\
\hline Nedd4 & ENSMUSG00000032216 & ENSG00000069869 \\
\hline Phkb & ENSMUSG00000036879 & ENSG00000102893 \\
\hline Braf & ENSMUSG00000002413 & ENSG00000157764 \\
\hline Macf1 & ENSMUSG00000028649 & ENSG00000127603 \\
\hline Ahcyl1 & ENSMUSG00000027893 & ENSG00000168710 \\
\hline Grm5 & ENSMUSG00000049583 & ENSG00000168959 \\
\hline Atpif1 & ENSMUSG00000054428 & ENSG00000130770 \\
\hline Mcfd2 & ENSMUSG00000024150 & ENSG00000180398 \\
\hline Myo6 & ENSMUSG00000033577 & ENSG00000196586 \\
\hline Cpne7 & ENSMUSG00000034796 & ENSG00000178773 \\
\hline Adcy1 & ENSMUSG00000020431 & ENSG00000164742 \\
\hline Agrn & ENSMUSG00000041936 & ENSG00000104490 \\
\hline Ncald & ENSMUSG00000051359 & ENSG00000188157 \\
\hline Dgkg & ENSMUSG00000022861 & ENSG00000058866 \\
\hline Dst & ENSMUSG00000026131 & ENSG00000067715 \\
\hline Syt1 & ENSMUSG00000035864 & ENSG00000151914 \\
\hline Fus & ENSMUSG00000030795 & ENSG00000089280 \\
\hline Chp1 & ENSMUSG00000014077 & ENSG00000187446 \\
\hline $\mathrm{Rbm} 22$ & ENSMUSG00000024604 & ENSG00000086589 \\
\hline Rab3gap1 & ENSMUSG00000036104 & ENSG00000115839 \\
\hline Sptan1 & ENSMUSG00000057738 & ENSG00000197694 \\
\hline Pdcd6ip & ENSMUSG00000032504 & ENSG00000170248 \\
\hline Camk1d & ENSMUSG00000039145 & ENSG00000183049 \\
\hline Usp32 & ENSMUSG00000000804 & ENSG00000143622 \\
\hline Rit1 & ENSMUSG00000028057 & ENSG00000170832 \\
\hline Sparc & ENSMUSG00000018593 & ENSG00000113140 \\
\hline Hspa5 & ENSMUSG00000026864 & ENSG00000044574 \\
\hline Spock1 & ENSMUSG00000056222 & ENSG00000152377 \\
\hline Ppm1f & ENSMUSG00000026181 & ENSG00000100034 \\
\hline
\end{tabular}

Differential expression analysis was done with DeSeq2 [17], considering genes with an adjusted $p$-value $<0.01$ and an absolute fold change $>2$ as significantly differentially expressed. DAVID resources [21,66] were used for enrichment analysis of Gene Ontology (GO) terms and biological pathways. Significantly enriched GO terms were considered with a $p$-value $<0.001$. The $\mathrm{CaGeDB}$ database [15] was utilized to identify calcium-related genes differentially expressed in each disorder compared to its controls. 
Table 4. Calcium-regulating signature genes identified in AS model mice.

\begin{tabular}{|c|c|c|}
\hline GeneSymbol & Ensemble_Mouse & Ensemble_human \\
\hline Cacna1g & ENSMUSG00000020866 & ENSG00000006283 \\
\hline Ppp3r1 & ENSMUSG00000033953 & ENSG00000221823 \\
\hline Fkbpla & ENSMUSG00000032966 & ENSG00000088832 \\
\hline Hsp90b1 & ENSMUSG00000020048 & ENSG00000166598 \\
\hline Sri & ENSMUSG00000003161 & ENSG00000075142 \\
\hline Calm1 & ENSMUSG00000001175 & ENSG00000198668 \\
\hline Rgs4 & ENSMUSG00000038530 & ENSG00000117152 \\
\hline Herpud1 & ENSMUSG00000031770 & ENSG00000051108 \\
\hline Ywhae & ENSMUSG00000020849 & ENSG00000108953 \\
\hline Gsto1 & ENSMUSG00000025068 & ENSG00000148834 \\
\hline Opa1 & ENSMUSG00000038084 & ENSG00000198836 \\
\hline Bnip3 & ENSMUSG00000078566 & ENSG00000176171 \\
\hline Nrxn1 & ENSMUSG00000024109 & ENSG00000179915 \\
\hline Arrb2 & ENSMUSG00000060216 & ENSG00000141480 \\
\hline Adcy3 & ENSMUSG00000020654 & ENSG00000138031 \\
\hline Fyn & ENSMUSG00000019843 & ENSG00000198947 \\
\hline Dmd & ENSMUSG00000045103 & ENSG00000010810 \\
\hline Calr & ENSMUSG00000003814 & ENSG00000179218 \\
\hline Slc9a1 & ENSMUSG00000028854 & ENSG00000090020 \\
\hline Stoml2 & ENSMUSG00000028455 & ENSG00000165283 \\
\hline Ppp3cb & ENSMUSG00000021816 & ENSG00000107758 \\
\hline Ddit3 & ENSMUSG00000025408 & ENSG00000175197 \\
\hline Stim2 & ENSMUSG00000039156 & ENSG00000109689 \\
\hline Micu1 & ENSMUSG00000020111 & ENSG00000107745 \\
\hline $\operatorname{Dlg} 4$ & ENSMUSG00000020886 & ENSG00000132535 \\
\hline Atp13a2 & ENSMUSG00000036622 & ENSG00000159363 \\
\hline Nptn & ENSMUSG00000032336 & ENSG00000156642 \\
\hline Gnb5 & ENSMUSG00000032192 & ENSG00000069966 \\
\hline Sgk1 & ENSMUSG00000019970 & ENSG00000118515 \\
\hline Tpt1 & ENSMUSG00000060126 & ENSG00000133112 \\
\hline
\end{tabular}

\section{Limitations of the Study}

The herein study was performed on publicly available datasets collected from NCBI resources. These datasets have a limited number of cases for each disorder, and the models of AS-like disorders include different organisms and different tissues. Nonetheless, despite the fact that the models of AS-like disorders are completely different, they all share the same calcium signatures and could all be identified based on the same gene signatures we determined using AS model mice. This highlights the molecular downstream pathways regulated by $U B E 3 A$ and which are also affected in other AS-like disorders. 
Supplementary Materials: The following are available online at https://www.mdpi.com/article/10 $.3390 / \mathrm{ijms} 22189870 / \mathrm{s} 1$.

Author Contributions: Conceptualization, H.K.; methodology, J.P. and H.K.; formal analysis, J.P. and H.K.; writing-original draft preparation, J.P. and H.K.; writing-review and editing, J.P. and H.K.; visualization, J.P.; supervision, H.K.; funding acquisition, H.K. All authors have read and agreed to the published version of the manuscript.

Funding: This work was supported by the Israel Science Foundation, Grant Number 248/20 (HK), and by the Angelman Syndrome Foundation (HK).

Institutional Review Board Statement: Not applicable.

Informed Consent Statement: Not applicable.

Data Availability Statement: All datasets used for the study are reported in Table 1 of this manuscript.

Conflicts of Interest: The authors declare no conflict of interest.

\section{References}

1. Angelman, H. 'Puppet' children a report on three cases. Dev. Med. Child Neurol. 2008, 7, 681-688. [CrossRef]

2. Williams, C.A.; Beaudet, A.L.; Clayton-Smith, J.; Knoll, J.H.; Kyllerman, M.; Laan, L.A.; Magenis, R.E.; Moncla, A.; Schinzel, A.A.; Summers, J.A.; et al. Angelman syndrome 2005: Updated consensus for diagnostic criteria. Am. J. Med. Genet. A 2006, 140, 413-418. [CrossRef]

3. Peters, S.U.; Beaudet, A.L.; Madduri, N.; Bacino, C.A. Autism in Angelman syndrome: Implications for autism research. Clin. Genet. 2004, 66, 530-536. [CrossRef]

4. Williams, C.A. Neurological aspects of the Angelman syndrome. Brain Dev. 2005, 27, 88-94. [CrossRef]

5. Summers, J.A.; Allison, D.B.; Lynch, P.S.; Sandier, L. Behaviour problems in Angelman syndrome. J. Intellect. Disabil. Res. 1995, 39, 97-106. [CrossRef]

6. Dan, B. Angelman syndrome: Current understanding and research prospects. Epilepsia 2009, 50, 2331-2339. [CrossRef] [PubMed]

7. Kishino, T.; Lalande, M.; Wagstaff, J. UBE3A/E6-AP mutations cause Angelman syndrome. Nat. Genet. 1997, 15, 70-73. [CrossRef] [PubMed]

8. Matsuura, T.; Sutcliffe, J.S.; Fang, P.; Galjaard, R.-J.; Jiang, Y.-H.; Benton, C.S.; Rommens, J.M.; Beaudet, A.L. De novo truncating mutations in E6-AP ubiquitin-protein ligase gene (UBE3A) in Angelman syndrome. Nat. Genet. 1997, 15, 74-77. [CrossRef]

9. Knoll, J.H.M.; Nicholls, R.D.; Magenis, R.E.; Graham, J.M.; Lalande, M.; Latt, S.A.; Opitz, J.M.; Reynolds, J.F. Angelman and Prader-Willi syndromes share a common chromosome 15 deletion but differ in parental origin of the deletion. Am. J. Med. Genet. 1989, 32, 285-290. [CrossRef] [PubMed]

10. Gustin, R.M.; Bichell, T.J.; Bubser, M.; Daily, J.; Filonova, I.; Mrelashvili, D.; Deutch, A.Y.; Colbran, R.J.; Weeber, E.J.; Haas, K.F. Tissue-specific variation of Ube3a protein expression in rodents and in a mouse model of Angelman syndrome. Neurobiol. Dis. 2010, 39, 283-291. [CrossRef] [PubMed]

11. Wallace, M.L.; Burette, A.C.; Weinberg, R.J.; Philpot, B.D. Maternal loss of Ube3a produces an excitatory/inhibitory imbalance through neuron type-specific synaptic defects. Neuron 2012, 74, 793-800. [CrossRef]

12. Sato, M.; Stryker, M.P. Genomic imprinting of experience-dependent cortical plasticity by the ubiquitin ligase gene Ube3a. Proc. Natl. Acad. Sci. USA 2010, 107, 5611-5616. [CrossRef]

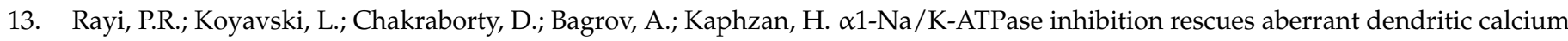
dynamics and memory deficits in the hippocampus of an Angelman syndrome mouse model. Prog. Neurobiol. 2019, $182,101676$. [CrossRef] [PubMed]

14. Panov, J.; Kaphzan, H. Bioinformatics analyses show dysregulation of calcium-related genes in Angelman syndrome mouse model. Neurobiol. Dis. 2021, 148, 105180. [CrossRef] [PubMed]

15. Hörtenhuber, M.; Toledo, E.; Smedler, E.; Arenas, E.; Malmersjö, S.; Louhivuori, L.; Uhlén, P. Mapping genes for calcium signaling and their associated human genetic disorders. Bioinformatics 2017, 33, 2547-2554. [CrossRef]

16. Tan, W.H.; Bird, L.M.; Thibert, R.L.; Williams, C.A. If not Angelman, what is it? A review of Angelman-like syndromes. Am. J. Med. Genet. Part A 2014, 164, 975-992. [CrossRef] [PubMed]

17. Love, M.I.; Huber, W.; Anders, S. Moderated estimation of fold change and dispersion for RNA-seq data with DESeq2. Genome Biol. 2014, 15, 1-21. [CrossRef] [PubMed]

18. Jollife, I.T.; Cadima, J. Principal component analysis: A review and recent developments. Philos. Trans. R. Soc. A Math. Phys. Eng. Sci. 2016, 374, 20150202. [CrossRef] [PubMed]

19. Jolliffe, I.T. Principal component analysis, second edition. Encycl. Stat. Behav. Sci. 2002, 30, 487. [CrossRef]

20. Huang, D.W.; Sherman, B.T.; Lempicki, R.A. Bioinformatics enrichment tools: Paths toward the comprehensive functional analysis of large gene lists. Nucleic Acids Res. 2009, 37, 1-13. [CrossRef] 
21. Huang, D.W.; Sherman, B.T.; Tan, Q.; Collins, J.R.; Alvord, W.G.; Roayaei, J.; Stephens, R.; Baseler, M.W.; Lane, H.C.; A Lempicki, R. The DAVID Gene Functional Classification Tool: A novel biological module-centric algorithm to functionally analyze large gene lists. Genome Biol. 2007, 8, R183. [CrossRef] [PubMed]

22. Amir, R.E.; Van Den Veyver, I.B.; Wan, M.; Tran, C.Q.; Francke, U.; Zoghbi, H.Y. Rett syndrome is caused by mutations in X-linked MECP2, encoding methyl- CpG-binding protein 2. Nat. Genet. 1999, 23, 185-188. [CrossRef] [PubMed]

23. Tillotson, R.; Bird, A. The molecular basis of MeCP2 function in the brain. J. Mol. Biol. 2020, 432, 1602-1623. [CrossRef] [PubMed]

24. Raman, A.T.; Pohodich, A.E.; Wan, Y.-W.; Yalamanchili, H.K.; Lowry, W.E.; Zoghbi, H.Y.; Liu, Z. Apparent bias toward long gene misregulation in MeCP2 syndromes disappears after controlling for baseline variations. Nat. Commun. 2018, 9, 1-13. [CrossRef] [PubMed]

25. Aldinger, K.A.; Timms, A.E.; Macdonald, J.W.; McNamara, H.K.; Herstein, J.S.; Bammler, T.K.; Evgrafov, O.V.; Knowles, J.A.; Levitt, P. Transcriptome data of temporal and cingulate cortex in the Rett syndrome brain. Sci. Data 2020, 7, 192. [CrossRef] [PubMed]

26. Marchetto, M.C.; Carromeu, C.; Acab, A.; Yu, D.; Yeo, G.W.; Mu, Y.; Chen, G.; Gage, F.H.; Muotri, A.R. A model for neural development and treatment of rett syndrome using human induced pluripotent stem cells. Cell 2010, 143, 527-539. [CrossRef]

27. Scaramuzza, L.; De Rocco, G.; Desiato, G.; Gigli, C.C.; Chiacchiaretta, M.; Mirabella, F.; Pozzi, D.; De Simone, M.; Conforti, P.; Pagani, M.; et al. The enhancement of activity rescues the establishment of Mecp2 null neuronal phenotypes. EMBO Mol. Med. 2021, 13, e12433. [CrossRef]

28. Kennedy, A.J.; Rahn, E.J.; Paulukaitis, B.S.; Savell, K.; Kordasiewicz, H.B.; Wang, J.; Lewis, J.W.; Posey, J.; Strange, S.K.; GuzmanKarlsson, M.C.; et al. Tcf4 regulates synaptic plasticity, DNA methylation, and memory function. Cell Rep. 2016, 16, 2666-2685. [CrossRef]

29. Zweier, C.; Peippo, M.M.; Hoyer, J.; Sousa, S.; Bottani, A.; Clayton-Smith, J.; Reardon, W.; Saraiva, J.M.; Cabral, A.; Göhring, I.; et al. Haploinsufficiency of TCF4 causes syndromal mental retardation with intermittent hyperventilation (Pitt-Hopkins syndrome). Am. J. Hum. Genet. 2007, 80, 994-1001. [CrossRef]

30. Li, H.; Zhu, Y.; Morozov, Y.M.; Chen, X.; Page, S.C.; Rannals, M.D.; Maher, B.J.; Rakic, P. Disruption of TCF4 regulatory networks leads to abnormal cortical development and mental disabilities. Mol. Psychiatry 2019, 24, 1235-1246. [CrossRef]

31. Phelan, K.; McDermid, H.E. The 22q13.3 deletion syndrome (Phelan-McDermid syndrome). Mol. Syndromol. 2012, 2, 186-201. [CrossRef] [PubMed]

32. Dhar, S.; del Gaudio, D.; German, J.; Peters, S.; Ou, Z.; Bader, P.; Berg, J.; Blazo, M.; Brown, C.; Graham, B.; et al. 22q13.3 Deletion syndrome: Clinical and molecular analysis using array CGH. Am. J. Med. Genet. Part A 2010, 152, 573-581. [CrossRef] [PubMed]

33. Sarasua, S.M.; Dwivedi, A.; Boccuto, L.; Rollins, J.D.; Chen, C.-F.; Rogers, R.C.; Phelan, K.; Dupont, B.R.; Collins, J.S. Association between deletion size and important phenotypes expands the genomic region of interest in Phelan-McDermid syndrome (22q13 deletion syndrome). J. Med. Genet. 2011, 48, 761-766. [CrossRef]

34. Naisbitt, S.; Kim, E.; Tu, J.C.; Xiao, B.; Sala, C.; Valtschanoff, J.; Weinberg, R.J.; Worley, P.F.; Sheng, M. Shank, a novel family of postsynaptic density proteins that binds to the NMDA receptor/PSD-95/GKAP complex and cortactin. Neuron 1999, 23, 569-582. [CrossRef]

35. Wang, W.; Li, C.; Chen, Q.; Van Der Goes, M.-S.; Hawrot, J.; Yao, A.Y.; Gao, X.; Lu, C.; Zang, Y.; Zhang, Q.; et al. Striatopallidal dysfunction underlies repetitive behavior in Shank3-deficient model of autism. J. Clin. Investig. 2017, 127, 1978-1990. [CrossRef]

36. Perfitt, T.L.; Wang, X.; Dickerson, M.T.; Stephenson, J.R.; Nakagawa, T.; Jacobson, D.A.; Colbran, R.J. Neuronal L-type calcium channel signaling to the nucleus requires a novel CaMKII $\alpha$-SHANK3 interaction. J. Neurosci. 2020, 40, 2000-2014. [CrossRef]

37. Breen, M.S.; Browne, A.; Hoffman, G.E.; Stathopoulos, S.; Brennand, K.; Buxbaum, J.D.; Drapeau, E. Transcriptional signatures of participant-derived neural progenitor cells and neurons implicate altered Wnt signaling in Phelan-McDermid syndrome and autism. Mol. Autism 2020, 11, 53. [CrossRef]

38. Koyavski, L.; Panov, J.; Simchi, L.; Rayi, P.R.; Sharvit, L.; Feuermann, Y.; Kaphzan, H. Sex-dependent sensory phenotypes and related transcriptomic expression profiles are differentially affected by Angelman syndrome. Mol. Neurobiol. 2019, 15, 5998-6016. [CrossRef]

39. Elsea, S.H.; Girirajan, S.S. Smith-Magenis syndrome. Eur. J. Hum. Genet. 2008, 16, 412-421. [CrossRef] [PubMed]

40. Buiting, K. Prader-Willi syndrome and Angelman syndrome. Am. J. Med. Genet. Part C Semin. Med. Genet. 2010, 154, 365-376. [CrossRef]

41. Smith Magenis Syndrome-NORD (National Organization for Rare Disorders) n.d. Available online: https://rarediseases.org/ rare-diseases / smith-magenis-syndrome/ (accessed on 5 June 2021).

42. Falco, M.; Amabile, S.; Acquaviva, F. The application of clinical genetics dovepress RAI1 gene mutations: Mechanisms of Smith-Magenis syndrome. Appl. Clin. Genet. 2017, 10, 85. [CrossRef]

43. Garay, P.M.; Chen, A.; Tsukahara, T.; Díaz, J.C.R.; Kohen, R.; Althaus, J.C.; Wallner, M.A.; Giger, R.J.; Jones, K.S.; Sutton, M.A.; et al. RAI1 Regulates activity-dependent nascent transcription and synaptic scaling. Cell Rep. 2020, 32, 108002. [CrossRef]

44. Bi, W.; Yan, J.; Shi, X.; Yuva-Paylor, L.A.; Antalffy, B.A.; Goldman, A.; Yoo, J.W.; Noebels, J.; Armstrong, D.L.; Paylor, R.; et al. Rai1 deficiency in mice causes learning impairment and motor dysfunction, whereas Rai1 heterozygous mice display minimal behavioral phenotypes. Hum. Mol. Genet. 2007, 16, 1802-1813. [CrossRef] [PubMed] 
45. Huang, W.-H.; Guenthner, C.J.; Xu, J.; Nguyen, T.; Schwarz, L.A.; Wilkinson, A.W.; Gozani, O.; Chang, H.Y.; Shamloo, M.; Luo, L. Molecular and neural functions of Rai1, the causal gene for Smith-Magenis syndrome. Neuron 2016, 92, 392-406. [CrossRef] [PubMed]

46. Ivanovski, I.; Djuric, O.; Caraffi, S.G.; Santodirocco, D.; Pollazzon, M.; Rosato, S.; Cordelli, D.M.; Abdalla, E.; Accorsi, P.; Adam, M.P.; et al. Phenotype and genotype of 87 patients with Mowat-Wilson syndrome and recommendations for care. Genet. Med. 2018, 20, 965-975. [CrossRef] [PubMed]

47. Birkhoff, J.C.; Huylebroeck, D.; Conidi, A. ZEB2, the Mowat-Wilson syndrome transcription factor: Confirmations, novel functions, and continuing surprises. Genes 2021, 12, 1037. [CrossRef]

48. Garavelli, L.; Ivanovski, I.; Caraffi, S.G.; Santodirocco, D.; Pollazzon, M.; Cordelli, D.M.; Abdalla, E.; Accorsi, P.; Adam, M.P.; Baldo, C.; et al. Neuroimaging findings in Mowat-Wilson syndrome: A study of 54 patients. Genet. Med. 2017, 19, 691-700. [CrossRef] [PubMed]

49. Gladka, M.; De Leeuw, A.; Kohela, A.; Molenaar, B.; Versteeg, D.; Kooijman, L.; Van Geldorp, M.; Van Rooij, E. ZEB2 regulates a transcriptional network of calcium-handling genes in the injured heart. Eur. Heart J. 2020, 41, ehaa946-3633. [CrossRef]

50. He, L.; Yu, K.; Lu, F.; Wang, J.; Wu, L.N.; Zhao, C.; Li, Q.; Zhou, X.; Liu, H.; Mu, D.; et al. Transcriptional regulator ZEB2 is essential for bergmann glia development. J. Neurosci. 2018, 38, 1575-1587. [CrossRef]

51. Hagerman, R.J.; Hagerman, P.J. The fragile X premutation: Into the phenotypic fold. Curr. Opin. Genet. Dev. 2002, 12, $278-283$. [CrossRef]

52. Ciaccio, C.; Fontana, L.; Milani, D.; Tabano, S.; Miozzo, M.; Esposito, S. Fragile X syndrome: A review of clinical and molecular diagnoses. Ital. J. Pediatr. 2017, 43, 1-12. [CrossRef]

53. Hagerman, P.J.; Stafstrom, C.E. Origins of epilepsy in fragile X syndrome. Epilepsy Curr. 2009, 9, 108-112. [CrossRef] [PubMed]

54. Salcedo-Arellano, M.J.; Dufour, B.; McLennan, Y.; Martinez-Cerdeno, V.; Hagerman, R. Fragile X syndrome and associated disorders: Clinical aspects and pathology. Neurobiol. Dis. 2020, 136, 104740. [CrossRef] [PubMed]

55. Richter, J.D.; Zhao, X. The molecular biology of FMRP: New insights into fragile X syndrome. Nat. Rev. Neurosci. 2021, 22, 209-222. [CrossRef] [PubMed]

56. Razak, K.A.; Dominick, K.C.; Erickson, C.A. Developmental studies in fragile X syndrome. J. Neurodev. Disord. 2020, 12. [CrossRef]

57. Utami, K.H.; Skotte, N.H.; Colaço, A.R.; Yusof, N.A.B.M.; Sim, B.; Yeo, X.Y.; Bae, H.-G.; Garcia-Miralles, M.; Radulescu, C.I.; Chen, Q.; et al. Integrative analysis identifies key molecular signatures underlying neurodevelopmental deficits in fragile $\mathrm{X}$ syndrome. Biol. Psychiatry 2020, 88, 500-511. [CrossRef]

58. Boniel, S.; Szymańska, K.; Śmigiel, R.; Szczałuba, K. Kabuki syndrome—Clinical review with molecular aspects. Genes 2021, $12,468$. [CrossRef]

59. Zhang, L.; Pilarowski, G.; Pich, E.M.; Nakatani, A.; Dunlop, J.; Baba, R.; Matsuda, S.; Daini, M.; Hattori, Y.; Matsumoto, S.; et al. Inhibition of KDM1A activity restores adult neurogenesis and improves hippocampal memory in a mouse model of Kabuki syndrome. Mol. Ther. Methods Clin. Dev. 2021, 20, 779-791. [CrossRef]

60. Van Laarhoven, P.M.; Neitzel, L.R.; Quintana, A.M.; Geiger, E.A.; Zackai, E.H.; Clouthier, D.E.; Artinger, K.B.; Ming, J.E.; Shaikh, T.H. Kabuki syndrome genes KMT2D and KDM6A: Functional analyses demonstrate critical roles in craniofacial, heart and brain development. Hum. Mol. Genet. 2015, 24, 4443-4453. [CrossRef]

61. Feliciano, D.M. The neurodevelopmental pathogenesis of tuberous sclerosis complex (TSC). Front. Neuroanat. 2020, 14, 39. [CrossRef]

62. Martin, K.; Zhou, W.; Bowman, M.; Shih, J.; Au, K.S.; Dittenhafer-Reed, K.; Sisson, K.A.; Koeman, J.; Weisenberger, D.J.; Cottingham, S.L.; et al. The genomic landscape of tuberous sclerosis complex. Nat. Commun. 2017, 8, 15816. [CrossRef]

63. Switon, K.; Kotulska, K.; Janusz-Kaminska, A.; Zmorzynska, J.; Jaworski, J. Tuberous sclerosis complex: From molecular biology to novel therapeutic approaches. IUBMB Life 2016, 68, 955-962. [CrossRef] [PubMed]

64. Grabole, N.; Zhang, J.D.; Aigner, S.; Ruderisch, N.; Costa, V.; Weber, F.C.; Theron, M.; Berntenis, N.; Spleiss, O.; Ebeling, M.; et al. Genomic analysis of the molecular neuropathology of tuberous sclerosis using a human stem cell model. Genome Med. 2016, 8, 1-14. [CrossRef]

65. Orlova, K.A.; Crino, P.B. The tuberous sclerosis complex. Ann. N. Y. Acad. Sci. 2010, 1184, 87-105. [CrossRef] [PubMed]

66. Huang, D.W.; Sherman, B.T.; Lempicki, R.A. Systematic and integrative analysis of large gene lists using DAVID bioinformatics resources. Nat. Protoc. 2009, 4, 44-57. [CrossRef] [PubMed] 